\title{
Coupled $\mathrm{Al} / \mathrm{Si}$ and $\mathrm{O} / \mathrm{N}$ order/disorder in $\mathrm{BaYb}\left[\mathrm{Si}_{4-x} \mathrm{Al}_{x} \mathrm{O}_{x} \mathrm{~N}_{7-x}\right]$ sialon: neutron powder diffraction and Monte Carlo simulations
}

\author{
Victor L. Vinograd ${ }^{*, \mathrm{I}}$, Erick A. Juarez-Arellano, Alexandra Lieb ${ }^{\mathrm{II},}$, , Karsten Knorr ${ }^{\mathrm{III}}$, Wolfgang Schnick ${ }^{\mathrm{II}}$, \\ Julian D. Gale ${ }^{\mathrm{IV}}$ and Björn Winkler ${ }^{\mathrm{I}}$ \\ I Institut für Geowissenschaften, Johann Wolfgang Göthe-Universität Frankfurt, Altenhöferallee 1, 60438 Frankfurt a. M., \\ Germany \\ II Department Chemie und Biochemie, Lehrstuhl für Anorganische Festkörperchemie, Ludwig-Maximilians-Universität München, \\ Butenandtstraße 5-13 (D), 81377 München, Germany

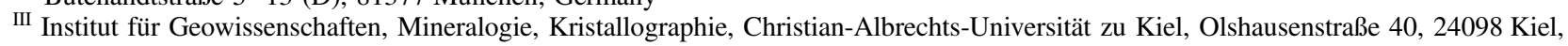 \\ Germany \\ IV Nanochemistry Research Institute, Department of Applied Chemistry, Curtin University of Technology, P.O. Box U1987, Perth 6845, \\ Western Australia
}

Received January 17, 2007; accepted March 21, 2007

\section{Oxonitridoaluminosilicate / Sialon / Cation and anion ordering / Substitution effects / Monte Carlo simulation / Neutron scattering / Powder diffraction structure analysis}

\begin{abstract}
The fractions of aluminium, $[\mathrm{Al}] /[\mathrm{Al}+\mathrm{Si}]$, and oxygen, $[\mathrm{O}] /[\mathrm{O}+\mathrm{N}]$, in crystallographically distinct sites of $\mathrm{BaYb}\left[\mathrm{Si}_{4-x} \mathrm{Al}_{x} \mathrm{O}_{x} \mathrm{~N}_{7-x}\right]$ oxonitridoaluminosilicate (space group $P 6_{3} m c$, No. 186) were refined based on the results of neutron powder diffraction for a synthetic sample with the composition of $x=2.2(2)$ and simulated as functions of temperature for the compositions $x=2$ and $x=2.3$ using a combination of static lattice energy calculations (SLEC) and Monte Carlo simulations. The SLEC calculations have been performed on a set of 800 structures differing in the distribution of $\mathrm{Al} / \mathrm{Si}$ and $\mathrm{O} / \mathrm{N}$ within the $2 \times 2 \times 2$ supercell containing 36 formula units of $\mathrm{BaYb}\left[\mathrm{Si}_{4-x} \mathrm{Al}_{x} \mathrm{O}_{x} \mathrm{~N}_{7-x}\right]$. The SLEC were based on a transferable set of empirical interatomic potentials developed within the present study. The static lattice energies of these structures have been expanded in the basis set of pair-wise ordering energies and on-site chemical potentials. The ordering energies and the chemical potentials have been used to calculate the configuration energies of the oxonitridoaluminosilicates (so-called sialons) using a Monte Carlo algorithm. The simulations suggest that $\mathrm{Al}$ and $\mathrm{O}$ are distributed unevenly over two non-equivalent $\mathrm{T}(\mathrm{Si} / \mathrm{Al})$ and three $\mathrm{L}(\mathrm{N} / \mathrm{O})$ sites, respectively, and the distribution shows strong dependence both on the temperature and the composition. Both simulated samples exhibit order/disorder transitions in the temperature range 500$1000 \mathrm{~K}$ to phases with partial long-range order below these
\end{abstract}

\footnotetext{
* Correspondence author (e-mail: v.vinograd@kristall.uni-frankfurt.de)

1 Present address: Université de Versailles St-Quentin en Yvelines, Institut Lavoisier, 45 Avenue des Etats Unis, 78035 Versailles Cedex, France.
}

temperatures. Above the transition temperatures the $\mathrm{Si} / \mathrm{Al}$ and N/O distributions are affected by short-range ordering. The predicted site occupancies are in a qualitative agreement with the neutron diffraction results.

\section{Introduction}

Oxonitridoaluminosilicates (sialons) are related to silicon nitrides via a $\mathrm{Si}+\mathrm{N}=\mathrm{Al}+\mathrm{O}$ exchange. The high mechanical and chemical stability of these compounds attracts technological interest (Hampshire, 1994; Thompson et al., 1996; Nordberg et al., 1998; Lauterbach et al., 2000). For technological applications it is important to characterise the structure, elasticity and thermodynamic properties of these compounds as a function of temperature, pressure and composition. For this purpose an optimized hightemperature synthesis approach utilizing high-frequency furnaces has been established (Schnick et al., 1999) and employed successfully to produce crystals suitable for the determination of the crystal structures of several sialon compounds, e.g. $\left.\mathrm{Sr}_{\mathrm{SiAl}} \mathrm{Si}_{3} \mathrm{~N}_{3}\right]$ (Lauterbach, Schnick, 1998); $\mathrm{Sr}_{10} \mathrm{Sm}_{6}\left[\mathrm{Si}_{30} \mathrm{Al}_{6} \mathrm{O}_{7} \mathrm{~N}_{54}\right]$ (Lauterbach, Schnick, 2000); $\mathrm{Nd}_{3}\left[\mathrm{Si}_{5} \mathrm{AlON}_{10}\right]$ (Lauterbach, Schnick, 2000); $\mathrm{Sr}_{3} L n_{10}\left[\mathrm{Si}_{18} \mathrm{Al}_{12} \mathrm{O}_{18} \mathrm{~N}_{36}\right]$ with $L n=\mathrm{Ce}, \mathrm{Pr}, \mathrm{Nd}$ (Lauterbach, et al., 2000); $\mathrm{BaSm}_{5}\left[\mathrm{Si}_{9} \mathrm{Al}_{3} \mathrm{~N}_{20}\right] \mathrm{O}$ (Lieb, Schnick, 2006).

The main problem with the experimental characterisation of sialons by X-ray diffraction is the similarity of the atomic form factors of $\mathrm{O}$ and $\mathrm{N}$ and of $\mathrm{Al}$ and Si. Thus the occupancy fractions of $\mathrm{Al}$ and $\mathrm{N}$ of crystallographically distinct sites cannot be determined using standard $\mathrm{X}$-ray diffraction methods, and therefore a statistically random distribution of $\mathrm{Al} / \mathrm{Si}$ and N/O is assumed for the majority of published sialon structures. Rietveld refinement based on neutron powder diffraction results, in principle, allows one to distinguish the $\mathrm{O} / \mathrm{N}$ and $\mathrm{Si} / \mathrm{Al}$ site occupancies in the sialons. However, both difficulties in the preparation of chemically homogeneous samples and the un- 
certainty associated with the chemical analysis of large samples can limit the ability to draw quantitative conclusions in certain cases.

The aim of this paper is to show that computer simulations can provide an important aid in the structural analysis of sialons. We show that a statistically random distribution of $\mathrm{Al} / \mathrm{Si}$ and $\mathrm{O} / \mathrm{N}$ is not a realistic assumption and that certain types of long-range and short-range order are to be expected in these materials. Our Monte Carlo simulations suggest that the site fractions reflect the effects of order and vary as functions of the temperature. Even at the synthesis temperature $(1473-2423 \mathrm{~K})$ there remains a significant distinction between the occupancies of different $\mathrm{T}(\mathrm{Al} / \mathrm{Si})$ and $\mathrm{L}(\mathrm{O} / \mathrm{N})$ sites. This prediction is consistent with the neutron diffraction results.

Furthermore, we show that the probable order/disorder scenario of sialons differs from the well understood $\mathrm{Al} / \mathrm{Si}$ ordering in framework and layer aluminosilicates. First of all, the connectivity of the $\mathrm{Al} / \mathrm{Si}$ sublattice of sialons differs from that of the $\mathrm{Al} / \mathrm{Si}$ frameworks of feldspars, cordierites and layer silicates, which typically contain 4-, 6and 8-membered rings of corner-sharing tetrahedra. The $\mathrm{Al} / \mathrm{Si}$ sublattice of $\mathrm{BaYb}\left[\mathrm{Si}_{4-x} \mathrm{Al}_{x} \mathrm{O}_{x} \mathrm{~N}_{7-x}\right]$ contains threemembered rings. These rings do not allow the avoidance of contacts between the tetrahedra occupied with the same cation and thus the regular alternation of corner-shared $\mathrm{Al}$ - and Si-centred tetrahedra, which is typical for ordered aluminosilicates, can not exist in sialons. On the other hand, sialons show the ability to develop $\mathrm{O} / \mathrm{N}$ anion ordering in parallel to the $\mathrm{Al} / \mathrm{Si}$ cation ordering. The identical charge difference of $\mathrm{O} / \mathrm{N}$ and $\mathrm{Al} / \mathrm{Si}$ supports local charge balance and brings about the possibility of building clusters of sites, which despite their chemical difference have the same total charge. Thus the sialons acquire the possibility of developing a variety of ordering schemes that can be interpreted as arrangements of clusters of identical charge. These clusters interact with each other rather weakly and, consequently, the order/disorder transitions occur at relatively low temperatures.

In this study we investigate the probable order/disorder scenarios for the two sialon compounds, $\mathrm{BaYb}\left[\mathrm{Si}_{2} \mathrm{Al}_{2} \mathrm{O}_{2} \mathrm{~N}_{5}\right]$ and $\mathrm{BaYb}\left[\mathrm{Si}_{1.7} \mathrm{Al}_{2.3} \mathrm{O}_{2.3} \mathrm{~N}_{4.7}\right]$, with the help of Monte Carlo simulations based on a parameterized force-field model. The empirical interatomic potentials, which are the basis of these simulations, are tested by comparing the predicted properties of the sialons with the results based on firstprinciples calculations.

\section{The crystal structure}

$\mathrm{BaYb}\left[\mathrm{Si}_{4-x} \mathrm{Al}_{x} \mathrm{O}_{x} \mathrm{~N}_{7-x}\right]$ (henceforth called $\mathrm{BaYb}$-sialon), is isotypic with the nitridosilicate $\mathrm{BaYb}\left[\mathrm{Si}_{4} \mathrm{~N}_{7}\right]$, which crystallises in the space group $P 6_{3} m c$ (hexagonal, No. 186) with unit cell parameters $a=6.0307(2) \AA$ and $c=9.8198(4) \AA$ (Huppertz and Schnick, 1997). In the $\mathrm{BaYb}\left[\mathrm{Si}_{4} \mathrm{~N}_{7}\right]$ structure the nitrogen atoms form a slightly distorted hexagonal dense packing $(h c p)$, where $2 / 3$ of the sites of the B layers in the $\mathrm{AB}$ stacking sequence are occupied. It is also observed that $3 / 8$ and $1 / 8$ of the tetrahedral voids in the alternating layers are filled with $\mathrm{Si}$ atoms. The $3 / 8$-filled layers can be also described in terms of three- and six-membered rings of corner-sharing $\left[\mathrm{SiN}_{4}\right]$ tetrahedra which are arranged perpendicular to the $c$-axis (Fig. 1a). These layers are connected along [001] via single $\left[\mathrm{SiN}_{4}\right]$ tetrahedra situated in the $1 / 8$-occupied layers. Because of this arrangement, the cation sites for Si split into two crystallographically different types, the so-called "ring" and "single" sites. Alternatively, the structure can be described by starshaped $\left[\mathrm{N}\left(\mathrm{NSi}_{3}\right)_{4}\right]$ building blocks (Fig. 1b), where the central $\mathrm{N}^{[4]}$ atom (henceforth called "star" site) simultaneously links four $\mathrm{Si}$ atoms. These building blocks are connected via the bridging $\mathrm{N}^{[2]}$ atoms (Fig. 1b). These bridging $\mathrm{N}^{[2]}$ sites split crystallographically into the "layer" and the "corner" types. The "layer" sites connect the starshaped units laterally within the layers, while the "corner" sites bridge the star-shaped units along the $c$ direction. The $\mathrm{Ba}^{2+}$ and $\mathrm{Yb}^{3+}$ cations occupy channels in the structure formed by $\mathrm{Si}_{6} \mathrm{~N}_{6}$-rings within the $3 / 8$-filled layers (Fig. 1a). The $\mathrm{Ba}^{2+}$ and $\mathrm{Yb}^{3+}$ ions are found in anticuboctahedral and octahedral coordination, respectively. In the $\mathrm{BaYb}\left[\mathrm{Si}_{4-x} \mathrm{Al}_{x} \mathrm{O}_{x} \mathrm{~N}_{7-x}\right]$ structure, $\mathrm{Si}^{4+}$ and $\mathrm{N}^{3-}$ atoms are partially replaced by $\mathrm{Al}^{3+}$ and $\mathrm{O}^{2-}$ atoms, respectively. The existence of the two non-equivalent cation sites ("ring" and "single") and the three anion sites ("star", "layer" and "corner") give rise to the possibility of $\mathrm{Al} / \mathrm{Si}$ and $\mathrm{O} / \mathrm{N}$ ordering.

(a)

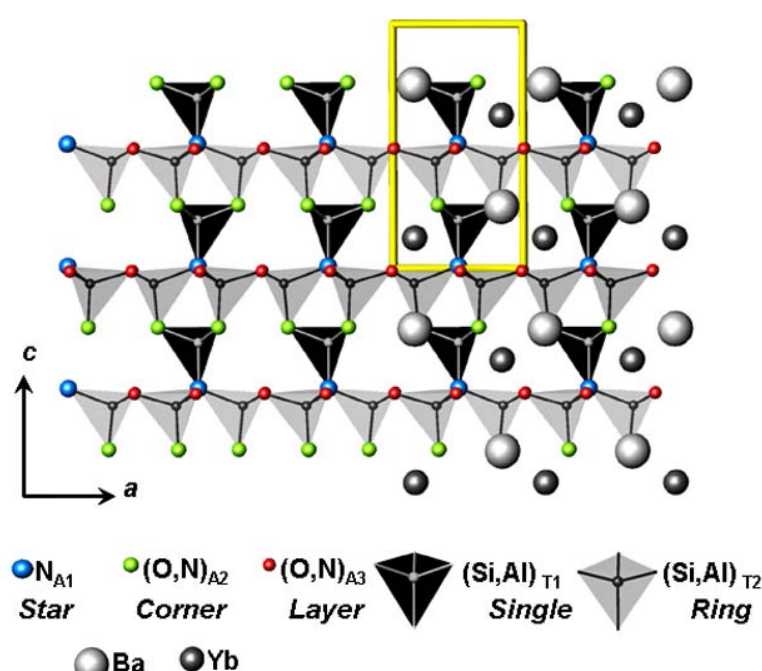

(b)

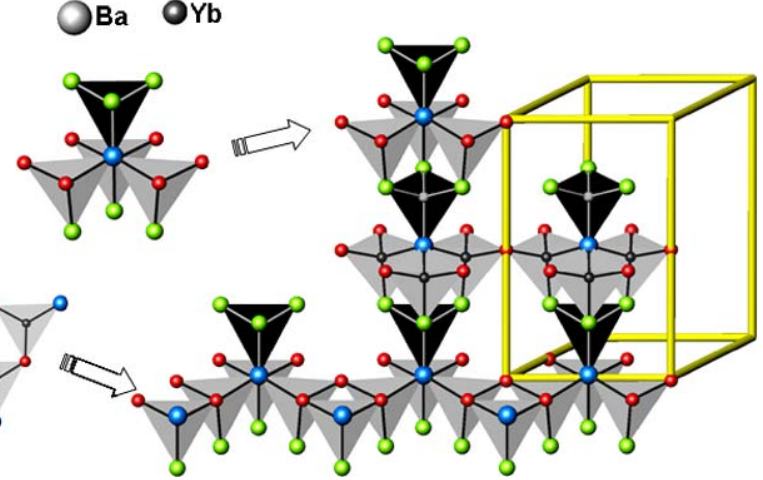

Fig. 1. The crystal structure of $\mathrm{BaYb}\left[\mathrm{Si}_{4-x} \mathrm{Al}_{x} \mathrm{O}_{x} \mathrm{~N}_{7-x}\right]$ : (a) Layers of the Si/Al "ring" (gray) and "single" (black) sites. (b) Rings of three $(\mathrm{Si} / \mathrm{Al})(\mathrm{N} / \mathrm{O})_{4}$ corner-sharing tetrahedra, star-shaped $[\mathrm{N}((\mathrm{Si} / \mathrm{Al})(\mathrm{N} /$ $\left.\left.\mathrm{O})_{3}\right)_{4}\right]$ units and their location in the structure. The crystallographically different $\mathrm{Si} / \mathrm{Al}$ tetrahedra and N/O sites are shown with different colours and sizes for a better visualisation. 


\section{Synthesis of $\mathrm{BaYb}\left[\mathrm{Si}_{4-x} \mathrm{Al}_{x} \mathrm{O}_{x} \mathrm{~N}_{7-x}\right]$}

A suitable sample for the neutron powder diffraction experiment was prepared according to the procedure of Lieb et al. (2007) which has been successfully used for the synthesis of $M L n\left[\mathrm{Si}_{4-x} \mathrm{Al}_{x} \mathrm{O}_{x} \mathrm{~N}_{7-x}\right]$ compounds, with $M=$ $\{\mathrm{Eu}, \mathrm{Sr}, \mathrm{Ba}\}$ and $L n=\{\mathrm{Ho}-\mathrm{Yb}\}$. The starting materials $\left(\mathrm{BaCO}_{3}, \mathrm{Yb}, \mathrm{Si}(\mathrm{NH})_{2}, \mathrm{AlN}\right.$ and $\mathrm{BaCl}_{2}$ as a flux $)$ were heated up to $1473 \mathrm{~K}$ within 1 hour, then kept at that temperature for 2 hours and finally heated up to $2423 \mathrm{~K}$ over a period of 4 hours. After that the sample was cooled to $1473 \mathrm{~K}$ during 60 hours and quenched to room temperature within about 40 minutes. To obtain about $80 \mathrm{mg}$ of $\mathrm{BaYb}\left[\mathrm{Si}_{4-x} \mathrm{Al}_{x} \mathrm{O}_{x} \mathrm{~N}_{7-x}\right]$ the reaction was performed 15 times and suitable single crystals were separated from the by-products, i.e. the so-called $J$-phase $\mathrm{Yb}_{4}\left[\mathrm{Si}_{2-x} \mathrm{Al}_{x} \mathrm{O}_{5+x} \mathrm{~N}_{2-x}\right] \mathrm{O}_{2}$ and some other amorphous sialon phases, which show different crystal habit and colour.

\section{Neutron powder diffraction}

The sample of $\mathrm{BaYb}\left[\mathrm{Si}_{4-x} \mathrm{Al}_{x} \mathrm{O}_{x} \mathrm{~N}_{7-x}\right]$ was obtained by collecting suitable single crystals using an optical microscope. The crystals were ground and used to fill a silicate glass capillary. Time-of-flight (TOF) powder neutron diffraction measurements were conducted at ambient temperature using the POLARIS diffractometer at ISIS/ Rutherford Appleton Laboratory, Chilton/UK. From the resulting four detector banks $\left(2 \theta: 14.0^{\circ}, 35.0^{\circ}, 90.0^{\circ}\right.$, $\left.145.0^{\circ}\right)$ the backscattering bank was used for the Rietveld refinement (using the program GSAS (Von Dreele and Larson, 2001)) owing to its relevant range of $d$-spacings from $d=0.16-3.18 \AA$ (TOF 1.0-19.6 ms). All reflections, except three very small ones from $\mathrm{Yb}_{4}\left[\mathrm{Si}_{2-x} \mathrm{Al}_{x} \mathrm{O}_{5+x} \mathrm{~N}_{2-x}\right] \mathrm{O}_{2}$, were indexed according to the hexagonal structure of $\mathrm{BaYb}\left[\mathrm{Si}_{4-x} \mathrm{Al}_{x} \mathrm{O}_{x} \mathrm{~N}_{7-x}\right]$, which is isostructural to the nitridosilicate $\mathrm{BaYb}\left[\mathrm{Si}_{4} \mathrm{~N}_{7}\right]$ (Huppertz and Schnick, 1996; $1997 \mathrm{a}, \mathrm{b})$. For the refinement a starting model based on the $\mathrm{X}$-ray single-crystal data of $\mathrm{BaYb}\left[\mathrm{Si}_{4-x} \mathrm{Al}_{x} \mathrm{O}_{x} \mathrm{~N}_{7-x}\right]$ (Lieb et al., 2007) was used. The positional and thermal displacement parameters were refined unconstrained and were found to be in good agreement with the single crystal data.

To obtain the site occupancy factors, initially $\mathrm{O} / \mathrm{N}$ and $\mathrm{Si} / \mathrm{Al}$ were distributed equally between their different crystallographic positions and the occupancy factor of each of these crystallographic sites were constrained to sum up to 1 to guarantee fully occupied sites. The refinement of all $\mathrm{O} / \mathrm{N}$ site occupancies lead to $\mathrm{O} /(\mathrm{N}+\mathrm{O})=0.02(2)$ for the "star" site, which was therefore fixed to zero. Further refinement resulted in the following occupancy ratios: [O]/ $[\mathrm{N}+\mathrm{O}]=0.39(2)$ for the "layer" site and $[\mathrm{O}] /[\mathrm{N}+\mathrm{O}]=$ $0.43(2)$ for the "corner" site. For the $\mathrm{Si} / \mathrm{Al}$ positions the refinement lead to $[\mathrm{Al}] /[\mathrm{Si}+\mathrm{Al}]=0.1(1)$ for the "single" site and $[\mathrm{Al}] /[\mathrm{Si}+\mathrm{Al}]=0.65(4)$ for the "ring" site. The Rietveld refinement of the data was difficult, compared to similar data of other sialons, due to a very slight peak splitting of all peaks of the $\mathrm{BaYb}\left[\mathrm{Si}_{4-x} \mathrm{Al}_{x} \mathrm{O}_{x} \mathrm{~N}_{7-x}\right]$ phase. This could indicate the presence of two slightly different
Table 1. Crystallographic data and details of the neutron diffraction data collection and the Rietveld refinement for $\mathrm{BaYb}\left[\mathrm{Si}_{2-x} \mathrm{Al}_{2+x} \mathrm{O}_{2+x} \mathrm{~N}_{5-x}\right]$.

\begin{tabular}{ll}
\hline Diffractometer & POLARIS, ISIS \\
Temperature/K & $293(2)$ \\
Space group & $P 6_{3} m c$ \\
Lattice parameter, $a / \AA$ & $6.08650(8)$ \\
$c / \AA$ & $9.90974(21)$ \\
Cell volume, $V / \AA^{3}$ & $317.928(9)$ \\
Detector position $2 \theta /^{\circ}$ & 145.0 \\
Scan mode & TOF \\
Observed reflections (backscattering bank) & 14763 \\
Goo $F$ & 2.72 \\
$R_{w p}$ & 0.034 \\
$R_{F 2}$ & 0.135 \\
Red. $\chi^{2}$ & 7.398 \\
\hline
\end{tabular}

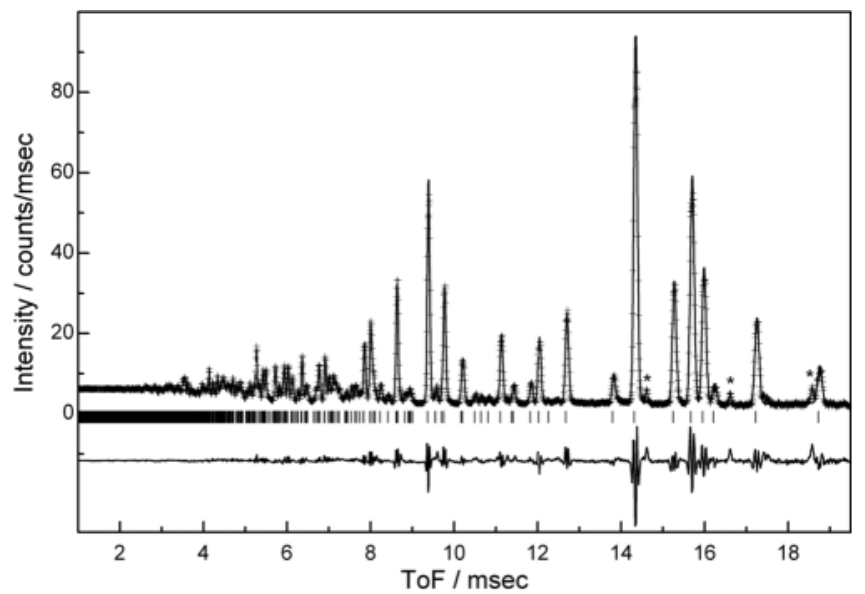

Fig. 2. Plot of the Rietveld refinement of the backscattering bank of the powder neutron data obtained for $\mathrm{BaYb}\left[\mathrm{Si}_{4-x} \mathrm{Al}_{x} \mathrm{O}_{x} \mathrm{~N}_{7-x}\right]$. The main reflections of the impurity $\mathrm{Yb}_{4}\left[\mathrm{Si}_{2-x} \mathrm{Al}_{x} \mathrm{O}_{5+x} \mathrm{~N}_{2-x}\right] \mathrm{O}_{2}$ are marked with asterisks.

compositions affecting the unit cell size. The peak splitting was included in the peak shape function; it could not be described with a multi phase refinement. The unusual behaviour is assumed to be a result of the sensitivity of this structure type to ordering effects, which depend on the chemical composition. As the sample was derived from 15 separate syntheses, a complete homogeneity could not be guaranteed. Relevant crystallographic data as well as details of the neutron diffraction data collection and the Rietveld refinement are shown in Table 1. The results of the refinement of the backscattering data are illustrated in Fig. $2^{2}$.

2 The positional and thermal displacement parameters and the occupancy factors for all atoms resulting from the refinement and further details of the structure refinement may be obtained from the Fachinformationszentrum Karlsruhe, D-76344 Eggenstein-Leopoldshafen, Germany, e-mail crysdata@FIZ-karlsruhe.de, by quoting the depository number CSD-417737. 
Table 2. Results of the chemical analyses of $\mathrm{BaYb}\left[\mathrm{Si}_{4-x} \mathrm{Al}_{x} \mathrm{O}_{x} \mathrm{~N}_{7-x}\right]$. For $\mathrm{O}$ and $\mathrm{N}$ only single analyses were performed.

\begin{tabular}{|c|c|c|c|c|c|c|c|}
\hline & $\mathrm{Ba}$ & $\mathrm{Yb}$ & $\mathrm{Si}$ & $\mathrm{Al}$ & $\mathrm{O}$ & $\mathrm{N}$ & Total \\
\hline measured (weight \%) & $23.1 / 23.2$ & $36.0 / 36.0$ & $10.7 / 10.7$ & $10.1 / 10.1$ & 7.1 & 11.8 & \\
\hline average (weight \%) & 23.15 & 36.0 & 10.7 & 10.1 & 7.1 & 11.8 & 98.85 \\
\hline average atom $\%$ & 7 & 9 & 16 & 15 & 18 & 35 & 100 \\
\hline normalised & 0.8 & 1 & 1.8 & 1.7 & 2 & 3.9 & \\
\hline $\begin{array}{l}\text { values calculated for } x=2 \\
\mathrm{BaYb}\left[\mathrm{Si}_{2} \mathrm{Al}_{2} \mathrm{O}_{2} \mathrm{~N}_{5}\right]\end{array}$ & 26.3 & 33.1 & 10.8 & 10.3 & 6.1 & 13.4 & \\
\hline atom $\%$ & 8 & 8 & 15 & 15 & 15 & 39 & 100 \\
\hline normalised & 1 & 1 & 2 & 2 & 2 & 5 & \\
\hline $\begin{array}{l}\text { values calculated for } x=2.3 \\
\mathrm{BaYb}\left[\mathrm{Si}_{1.7} \mathrm{Al}_{2.3} \mathrm{O}_{2.3} \mathrm{~N}_{4.7}\right]\end{array}$ & 26.3 & 33.1 & 9.1 & 11.9 & 7.0 & 12.6 & \\
\hline atom $\%$ & 8 & 8 & 12 & 18 & 18 & 36 & 100 \\
\hline normalised & 1 & 1 & 1.7 & 2.3 & 2.3 & 4.7 & \\
\hline
\end{tabular}

\section{Elemental analysis}

After the neutron diffraction experiment the same sample was used for chemical analysis performed by Mikroanalytisches Labor Pascher (Remagen, Germany). Each element of the sample (about $50 \mathrm{mg}$ ) was analysed twice, except $\mathrm{O}$ and $\mathrm{N}$, for which only a single analysis was possible. The precision of the used methods is claimed to be $\approx 0.5 \%$ for $\mathrm{O}, \mathrm{N}, \mathrm{Si}, \mathrm{Al}$ and $\approx 1 \%$ for $\mathrm{Ba}, \mathrm{Yb}$, but in the case of a single analysis it could be lower. The results are listed in Table 2. The elemental analysis (Table 2) shows some disagreements with the theoretical formula values, which are assumed to be due to the very difficult digestion process for the extremely stable sialon compounds, the presence of small amounts of $\mathrm{Yb}_{4}\left[\mathrm{Si}_{2-x} \mathrm{Al}_{x} \mathrm{O}_{5+x} \mathrm{~N}_{2-x}\right] \mathrm{O}_{2}$ as an impurity, and the imprecise measurement of $\mathrm{O}$ and $\mathrm{N}$. Generally the analysis agrees with both possibilities for the formula of $\mathrm{BaYb}\left[\mathrm{Si}_{4-x} \mathrm{Al}_{x} \mathrm{O}_{x} \mathrm{~N}_{7-x}\right]$ with $x=2$ and $x=2.3$.

\section{Simulation procedure}

Recent progress in quantitative simulation of the effects of ordering in silicates and oxides (Thayaparam et al., 1996; Bosenick et al., 2001; Warren et al., 2001; Becker and Pollock, 2002; Vinograd et al., 2006) has been supported by the development of accurate parameterisation schemes for interatomic interactions in ionic materials (Lewis and Catlow, 1985; Bush et al., 1994; Patel et al., 1991; Winkler et al., 1991) and of the software tools for lattice energy minimisation calculations (Gale, 1997; Gale \& Rohl, 2003). It is also important that the predictive ability of the forcefield parameterisation can now be tested against the robust results obtained for the same compounds with the density functional theory (Hohenberg and Kohn, 1964; Kohn and Sham, 1965; Parr and Yang, 1989; Jones and Gunnarsson, 1989; Kryachko and Ludena, 1990). All this offers the possibility of accurately calculating static lattice energies of a variety of configurations differing in the distribution of the exchangeable atoms $(e a)$ within a supercell of a reasonably large size $(\sim 100-500 e a)$ and thus to investigate the most important ordering interactions and ordering schemes. The most difficult problem in the modelling of disordered systems consists in the necessity of dealing with an enormous number of possible configurations differing in the atomic arrangement and in the lattice energy. The great break-through in this problem was achieved with the development of the cluster expansion (Connolly \& Williams, 1983; Sanchez et al. 1984); a procedure that allows the mapping of the energy of any configuration within a supercell onto a set of local ordering (or cluster) interactions. When the cluster expansion converges reasonably fast with the increase of the cluster size, it can be used to calculate configuration energies in much larger supercells (2000-5000 ea). The thermal averages of the configurational energy calculated for systems of this size approach those of an infinite lattice. These averages can be obtained with the help of Monte Carlo simulations. Other thermodynamically important functions, such as the configurational entropy and free energy, can be calculated from the average energies using the method of thermodynamic integration (Myers et al., 1998; Myers, 1999; Warren et al., 2001). This study is aimed at applying these tools to oxonitridoaluminosilicates. The simulation procedure is organised according to the following plan:

- Development of a set of transferable empirical interatomic potentials by fitting to structure and elasticity data of chemically similar minerals.

- Testing the potentials by comparing the predicted properties of a limited set of ordered structures with the results of quantum mechanical calculations.

- Static lattice energy calculations (SLEC) on a large set of structures with randomly varied cation configurations.

- Finding a simple equation that describes the energies of the simulated structures. This procedure is known as the 'cluster expansion'.

- Using the cluster expansion model to obtain temperature-dependent properties by Monte Carlo simulations.

- Calculation of the free energies and entropies of disordering by thermodynamic integration of the Monte Carlo results.

\section{Interatomic potential derivation}

A set of empirical interatomic potentials for $\mathrm{Ba}-\mathrm{Sr}-\mathrm{Y}-\mathrm{Yb}-\mathrm{Si}-\mathrm{Al}-\mathrm{O}-\mathrm{N}$ system was developed in this study using the relax-fitting procedure (Gale, 1996) as 
implemented in the GULP program (Gale, 1997; Gale and Rohl, 2003). The procedure involves simultaneous static lattice energy calculations (SLEC) on a number of chemically similar structures. Within the procedure, the parameters of the empirical potential functions are varied in the search for the minimum in the discrepancy between the calculated and observed structure, energy and/or elasticity constraints. The set of potentials involves two-body Metal-Anion (M-A, $\mathrm{A} \in\left\{\mathrm{O}^{2-}, \mathrm{N}^{3}\right\}$ ) Buckingham potentials, three-body $\mathrm{A}-\mathrm{M}-\mathrm{A}$ bond-bending terms and the shell model for the anion polarizability, as described by Sanders et al. (1984), Patel et al. (1991) and Winkler et al. (1991). Following Vinograd et al. (2004), we multiplied formal cation and anion charges by the common factor 0.85 , so that the charges of 2-, 3- and 4-valent ions have been reduced to the values of $1.7,2.55$ and 3.4 , respectively. Such a reduction has already permitted the development of a set of potentials for the $\mathrm{Mg}-\mathrm{Al}-\mathrm{Si}-\mathrm{O}$ system (Vinograd et al. 2006, 2007), which showed good transferability within a large number of silicate and aluminosilicate structures of different density. The reduction factor of 0.85 was obtained on a purely empirical basis. The potentials set for the $\mathrm{Si}-\mathrm{Al}-\mathrm{O}$ subsystem has been developed first by fitting to structure and elasticity data on $\alpha$-quartz, coesite, stishovite and corundum. The structure data and the elastic stiffness constants have been taken from the ICSD data base (National Institute of Standards, Release 2006/2) and from the review of Bass (1995). In the second step, the potentials were refined by including in the fit the structure and elasticity data on kyanite, sillimanite and andalusite. It was observed that the potentials fitted to $\mathrm{SiO}_{2}$ polymorphs and corundum reproduce the unit-cell parameters and the elastic stiffness constants of $\mathrm{Al}_{2} \mathrm{SiO}_{5}$ polymorphs very well and require only a slight correction. These potentials together with the $\mathrm{Mg}-\mathrm{O}$ potential fitted to the structure and elasticity data on $\mathrm{MgO}$-periclase, $\mathrm{MgSiO}_{3}$-ilmenite, $\mathrm{Mg}_{2} \mathrm{SiO}_{4}$-forsterite and $\mathrm{Mg}_{2} \mathrm{SiO}_{4}$-spinel permit a nearly quantitative description of the structure, elasticity and $\mathrm{Al} / \mathrm{Si}$ order/disorder data on $\mathrm{Mg}_{3} \mathrm{Al}_{4} \mathrm{Si}_{5} \mathrm{O}_{18^{-}}$ cordierite (Vinograd et al. 2007). We hope that this set will permit one to accurately model $\mathrm{Al}-\mathrm{Si}$ ordering in the sialons, too. In order to use the already developed potentials for aluminosilicates and preserve consistency, we have assumed that the $\mathrm{N}-\mathrm{N}$ and $\mathrm{N}-\mathrm{O}$ and $\mathrm{M}-\mathrm{N}$ interactions can be described within the same shell model. The $\mathrm{N}($ shell $)-\mathrm{N}$ (shell), $\mathrm{N}($ core $)-\mathrm{N}($ shell $), \quad \mathrm{N}($ shell $)-\mathrm{Si}$ (core) and the three-body $\mathrm{N}$ (shell) $-\mathrm{Si}($ core $)-\mathrm{N}$ (shell) potentials have been fitted to the structural and elasticity data of the $\alpha$ and $\beta$ polymorphs of $\mathrm{Si}_{3} \mathrm{~N}_{4}$ (Toraya, 2000; Schneider et al., 1994; Ching, et al., 2000 and references therein). The parameters of the Buckingham N(shell) $-\mathrm{O}$ (shell) potential were fitted to the structure and bulk-modulus data on sinoite, $\mathrm{Si}_{2} \mathrm{~N}_{2} \mathrm{O}$ (Srinivasa et al. 1977) and the structure of $\mathrm{Y}_{2} \mathrm{Si}_{3} \mathrm{O}_{3} \mathrm{~N}_{4}$ melilite (Wang et al. 1997). The $\mathrm{Y}-\mathrm{N}$ and $\mathrm{Y}-\mathrm{O}$ Buckingham potentials needed for the description of $\mathrm{Y}_{2} \mathrm{Si}_{3} \mathrm{O}_{3} \mathrm{~N}_{4}$ melilite have been fitted to the structure data of YN (Holleck \& Smailos, 1980), Y-garnet, $\mathrm{Y}_{3} \mathrm{Al}_{5} \mathrm{O}_{12}$ (Chernaya et al. 1987) and structure and elasticity data on $\mathrm{Y}_{2} \mathrm{O}_{3}$ (Fert, 1962; Palko et al. 2001). The Buckingham $\mathrm{Al}-\mathrm{N}$ and the three-body $\mathrm{O}-\mathrm{Al}-\mathrm{N}$ and $\mathrm{O}-\mathrm{Si}-\mathrm{N}$ potentials were fitted to the structure data of $\mathrm{Si}_{3} \mathrm{Al}_{3} \mathrm{O}_{3} \mathrm{~N}_{5}$ (van
Dijen et al., 1987), $\mathrm{Si}_{5} \mathrm{AlON}_{7}$ (Khvatinskaya et al., 1991) and $\mathrm{Si}_{2} \mathrm{Al}_{4} \mathrm{O}_{4} \mathrm{~N}_{4}$ (Gillott et al., 1981). The $\mathrm{Sr}-\mathrm{O}$ and $\mathrm{Ba}-\mathrm{O}$ potentials were fitted to the structures of celsian (Benna \& Bruno 2001) and Ba- and Sr-garnets (Novak \& Gibbs, 1971). The $\mathrm{Sr}-\mathrm{N}$ and $\mathrm{Ba}-\mathrm{N}$ potentials were fitted to the structures of $\mathrm{Ba}_{3} \mathrm{Al}_{2} \mathrm{~N}_{4}$ (Ludwig et al., 1999) and $\mathrm{Sr}_{3} \mathrm{Al}_{2} \mathrm{~N}_{4}$ (Blase et al., 1994). The $\mathrm{Yb}-\mathrm{O}$ potential was fitted to the structure data of $\mathrm{Yb}_{2} \mathrm{O}_{3}$ (Heiba et al., 2003), while the $\mathrm{Yb}-\mathrm{N}$ potential was fitted to the structure data of YbN (Doenni et al., 1984) and SrYb- and BaYb-nitridosilicates (Huppertz, \& Schnick 1997). The experimentally determined bulk moduli of SrYb- and BaYb-sialons (162(2) and 168(2) GPa, respectively; Juarez-Arellano et al., 2006) were also used in the fit. The final set of potentials is given in Table 3.

Table 3. The empirical interatomic potential parameters used in the present study.

\begin{tabular}{|c|c|c|c|}
\hline $\begin{array}{l}\text { Buckingham, } \\
A \exp (-r / B)-C / r^{6}\end{array}$ & $A(\mathrm{eV})$ & $B(\AA)$ & $C\left(\mathrm{eV} \AA^{6}\right)$ \\
\hline $\mathrm{Ba}[6-8]-\mathrm{O}$ (shell) & 6134.1232 & 0.276377 & 0.0 \\
\hline $\mathrm{Ba}[6-8]-\mathrm{N}($ shell $)$ & 90185.816 & 0.237234 & 0.0 \\
\hline $\operatorname{Sr}[6-8]-\mathrm{O}$ (shell) & 3037.5032 & 0.286360 & 0.0 \\
\hline $\operatorname{Sr}[6-8]-N($ shell $)$ & 65861.945 & 0.229448 & 0.0 \\
\hline $\mathrm{Al}[4,6]-\mathrm{O}$ (shell) & 1115.6866 & 0.291905 & 0.0 \\
\hline $\mathrm{Al}[4,6]-\mathrm{N}($ shell $)$ & 940.13011 & 0.346478 & 0.0 \\
\hline $\operatorname{Mg}[6,8]-\mathrm{O}($ shell $)$ & 1190.5254 & 0.284037 & 0.0 \\
\hline $\mathrm{Si}[4,6]-\mathrm{O}($ shell $)$ & 995.92238 & 0.304057 & 0.0 \\
\hline Si[4]-N(shell) & 938.37747 & 0.360014 & 0.0 \\
\hline $\mathrm{Yb}[6]-\mathrm{O}$ (shell) & 526.08515 & 0.387476 & 0.0 \\
\hline $\mathrm{Yb}[6]-\mathrm{N}($ shell $)$ & 605.76519 & 0.423286 & 0.0 \\
\hline $\mathrm{Y}[6]-\mathrm{O}($ shell $)$ & 1754.3763 & 0.314788 & 0.0 \\
\hline Y[6]-N(shell) & 1799.4002 & 0.348502 & 0.0 \\
\hline $\mathrm{O}($ shell $)-\mathrm{O}($ shell $)$ & 593.05553 & 0.321826 & 29.61488 \\
\hline $\mathrm{O}($ shell $)-\mathrm{N}($ shell $)$ & 670.99609 & 0.331623 & 131.6915 \\
\hline $\mathrm{N}($ shell) $-\mathrm{N}($ shell) & 111.43379 & 0.357888 & 233.7556 \\
\hline Spring, $1 / 2 K r^{2}$ & $K\left(\mathrm{eV} \AA^{-2}\right)$ & & \\
\hline $\mathrm{O}($ core $)-\mathrm{O}($ shell $)$ & 56.663970 & & \\
\hline $\mathrm{N}($ core $)-\mathrm{N}($ shell $)$ & 62.793576 & & \\
\hline
\end{tabular}

\begin{tabular}{|c|c|c|}
\hline Three-body, $1 / 2 Q\left(\theta-\theta_{0}\right)^{2}$ & $Q\left(\mathrm{eV}\right.$ degree $\left.{ }^{-2}\right)$ & $\theta_{0}$ (degrees) \\
\hline $\mathrm{O}($ shell $)-\mathrm{Mg}[6]-\mathrm{O}$ (shell) & 1.0514 & 90.0 \\
\hline $\mathrm{O}($ shell $)-\mathrm{Si}[4]-\mathrm{O}($ shell $)$ & 2.5171 & 109.47 \\
\hline $\mathrm{N}($ shell $)-\mathrm{Si}[4]-\mathrm{N}($ shell $)$ & 7.4425 & 109.47 \\
\hline $\mathrm{N}($ shell $)-\mathrm{Si}[4]-\mathrm{O}$ (shell) & 6.2173 & 109.47 \\
\hline $\mathrm{O}($ shell $)-\mathrm{Si}[6]-\mathrm{O}$ (shell) & 2.9253 & 90.0 \\
\hline $\mathrm{O}($ shell $)-\mathrm{Al}[4]-\mathrm{O}($ shell $)$ & 1.0372 & 109.47 \\
\hline $\mathrm{N}($ shell $)-\mathrm{Al}[4]-\mathrm{N}($ shell $)$ & 0.74377 & 109.47 \\
\hline $\mathrm{N}($ shell $)-\mathrm{Al}[4]-\mathrm{O}($ shell $)$ & 1.4696 & 109.47 \\
\hline $\mathrm{O}($ shell $)-\mathrm{Al}[6]-\mathrm{O}($ shell $)$ & 1.7947 & 90.0 \\
\hline
\end{tabular}

Note: The charges on the oxygen core and shell are 0.751575 and -2.451575 , respectively. The charges on the nitrogen core and shell are 0.843862 and -3.393862 , respectively. $r$ is interatomic distance and $\Theta$ is the angle between two cation-anion vectors. Cutoff distance for the Buckingham potentials is $12 \AA$. 


\section{Quantum mechanical calculations as a test for the accuracy of the potentials}

To test the accuracy of the empirical potentials in reflecting the structural properties of the sialons $\mathrm{BaYb}\left[\mathrm{Si}_{2} \mathrm{Al}_{2} \mathrm{O}_{2} \mathrm{~N}_{5}\right]$ and $\mathrm{BaYb}\left[\mathrm{Si}_{1.7} \mathrm{Al}_{2.3} \mathrm{O}_{2.3} \mathrm{~N}_{4.7}\right]$ we compare the SLEC results with parameter-free quantum mechanical calculations for three compositional variants (1), (2) and (3) differing in fractional occupancies of $\mathrm{Al}$ and $\mathrm{O}$ in cation and anion sites. In all the three structures the star site was fully occupied by $\mathrm{N}$. The structure of (1) was constructed to have statistically equal distribution of $\mathrm{Al} / \mathrm{Si}$ and N/O both be- tween the ring and single sites and between the corner and layer sites. In the structure of (2) the single site was assumed be fully occupied by $\mathrm{Si}$, while the N/O ratio was assumed to be equal for the corner and layer sites. This equality was violated in the structure of (3), where the concentration of $\mathrm{O}$ was increased in the "layer" sites. The quantum mechanical calculations were based on density functional theory (DFT) with the exchange and correlation energies being treated based on the generalised gradient approximation (GGA), in the form proposed by Perdew, Burke and Ernzerhof (PBE) (1996). Here we used the computational scheme in which the charge density and

Table 4. Correlation between the experimental and calculated structural parameters of the sialons.

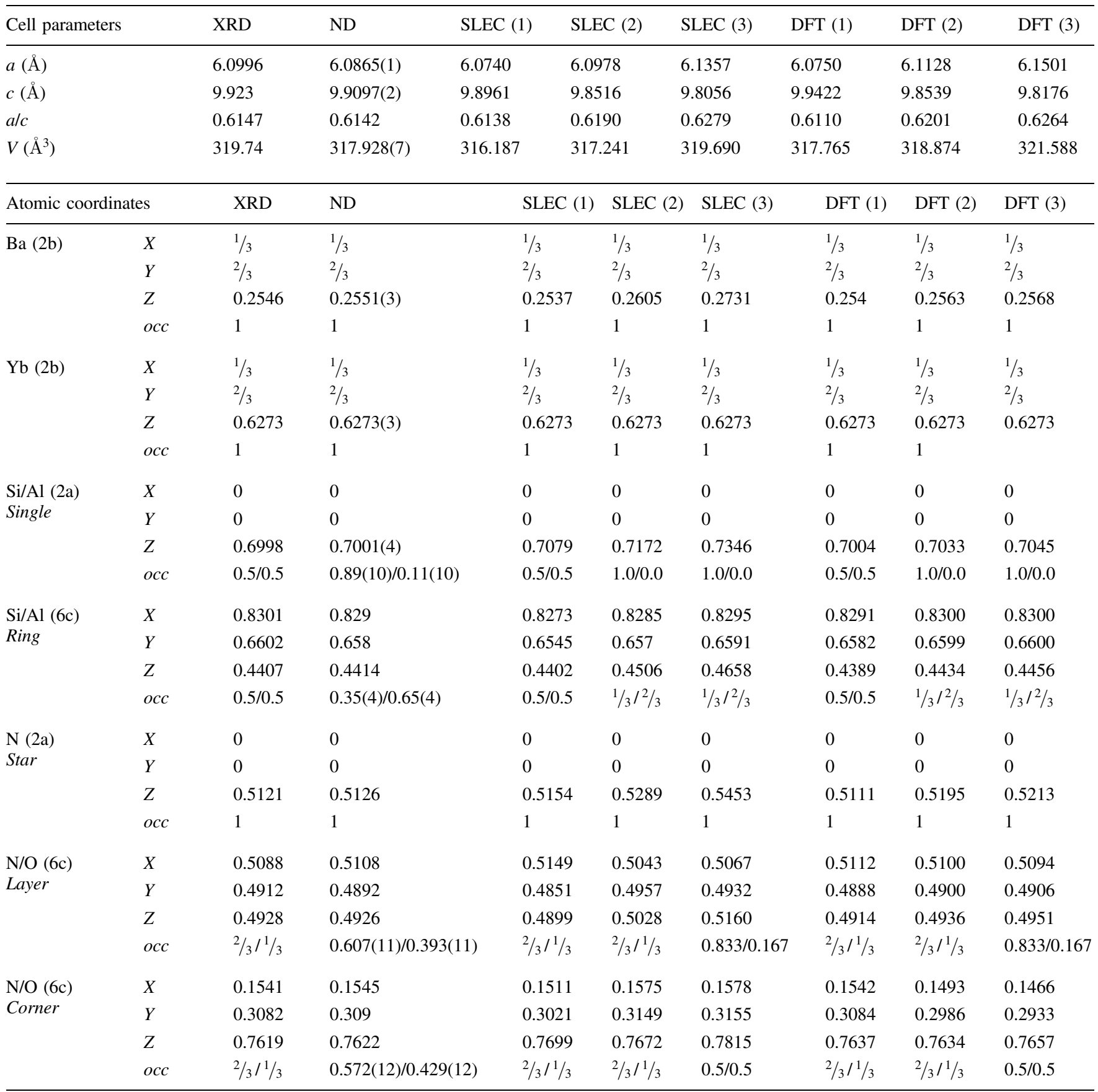

Note: XRD - X-ray diffraction data (Lieb et al., 2007); ND - neutron diffraction data (this study); SLEC-Static lattice energy calculations using the force-field parameters developed in the study; DFT - first principles calculations based on DFT GGA and virtual crystal approximation. The structures 1, 2 and 3 differ in the occupancies of the cation and anion sites. 


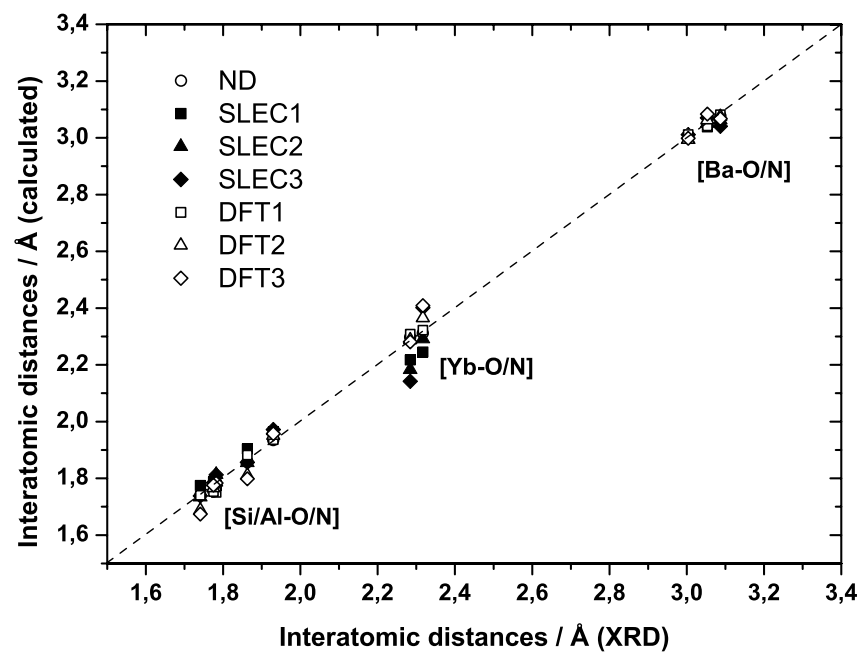

Fig. 3. Correlation between the experimental and calculated cationanion distances in the three sialon structures.

electronic wavefunctions are expanded in a basis set of plane waves. To avoid explicit description of tightly bound core electrons, the approach employs 'ultrasoft' pseudopotentials (Vanderbilt, 1990; Kresse and Hafner, 1994), which mimic the screening of the Coulomb potential of the nucleus by the core electrons. Both academic and commercial versions of CASTEP (Clark et al., 2005) were used in the present study. Calculations were performed with the hexagonal, $P 6_{3} m c$, symmetry using the primitive cell. The $k$-point sampling was performed using a $4 \times 4 \times 4$ Monkhorst-Pack grid in the $1^{\text {st }}$ Brillouin zone. The cut-off energy for the plane wave expansion was $380 \mathrm{eV}$. The fractional occupancies were treated within the virtual crystal approximation (VCA) which is based on weighting of the contributions of the pseudopotentials according to the site fractions (Winkler et al., 2002; Wilson et al., 2007). In these calculations, all symmetry independent structural parameters were varied simultaneously in the search for the ground state geometry. The parameters of the 'relaxed' (optimized) structures are given in Table 4, where they are compared to experimental values and to the results of the calculations based on the empirical potentials. Figure 3 shows the correlation between the experimentally observed and predicted cation-oxygen distances. Both the first principles and the SLEC predicted structural parameters are in good agreement with the experimental data of Lieb et al. (2006, 2007). This agreement validates the use of the computationally less demanding force-field approach in a more extensive examination of the relative stability of disorder structures.

\section{The supercell static lattice energy calculations (SLEC)}

Using the GULP program, we have calculated the static energies of about 800 structures with different $\mathrm{Al} / \mathrm{Si}$ and $\mathrm{O} / \mathrm{N}$ arrangements in the supercell of the $P 6_{3} m c$ sialon. We used a $2 \times 2 \times 2$ supercell containing 144 exchangeable cation sites and 252 anion sites. Two different compositions have been investigated. The two initial structures were chosen to have $\mathrm{Ba}_{36} \mathrm{Yb}_{36} \mathrm{Si}_{72} \mathrm{Al}_{72} \mathrm{O}_{72} \mathrm{~N}_{180}$ and
$\mathrm{Ba}_{36} \mathrm{Yb}_{36} \mathrm{Si}_{61} \mathrm{Al}_{83} \mathrm{O}_{83} \mathrm{~N}_{169}$ compositions. The two models that correspond to these compositions will be subsequently referred to as $A$ and $B$ sialons. The difference in the compositions of the sialons $A$ and $B$ covers approximately the uncertainty range of the composition of the sample studied with neutron diffraction. The "star" site in the initial structures was fully occupied with nitrogen. Otherwise, the $\mathrm{Al} / \mathrm{Si}$ and N/O arrangements were chosen randomly. The other structures have been generated by random swapping of $\mathrm{Al}$ and $\mathrm{Si}$, and $\mathrm{O}$ and $\mathrm{N}$ atoms. The swapping has been repeated 300 times for each of the structures. Another two sets of 100 structures each were generated using a different method, which is described in a later section. For each of the generated configurations we have calculated a set of statistical characteristics that included the fractions of Al and $\mathrm{O}$ in the five non-equivalent sites and the probabilities of finding $\mathrm{Al}-\mathrm{Si}, \mathrm{O}-\mathrm{N}, \mathrm{Al}-\mathrm{O}$ and $\mathrm{Si}-\mathrm{N}$ pairs at different interatomic distances.

\section{Cluster expansion}

The aim of the cluster expansion is to get a simple equation, which fits the energies of all simulated configurations and, hopefully, predicts the energy of any other possible configuration. One popular form for such an expansion is known as the $J$ s formalism (e.g. Becker et al., 2000; Bosenick et al., 2001; Vinograd et al., 2006a);

$$
E \approx 1 / 2 \sum_{l \neq m} \sum_{n} z^{(n)} P_{l m^{(n)}} J_{l m^{(n)}}+\sum_{k} \sum_{i} P_{i^{(k)}} \mu_{i^{(k)}}+E_{0}
$$

where $z^{(n)}, P_{l m^{(n)}}, P_{i^{(k)}}, J_{l m^{(n)}}$ and $\mu_{i^{(k)}}$ are the coordination numbers, frequencies of $l m$-type pairs $(\mathrm{Al}-\mathrm{Si}, \mathrm{O}-\mathrm{N}, \mathrm{Al}-\mathrm{O}$ and $\mathrm{Si}-\mathrm{N}$ ), probabilities to find an atom of type $i$ in $k$-site, ordering constants for pairs of the order $n$ and the on-site chemical potentials of $i$-type atoms, respectively. $J_{I m^{(n)}}$ corresponds to the energy of the exchange reaction $l l+m m=l m+m l$ between atoms $l \in\{\mathrm{Al}, \mathrm{Si}, \mathrm{O}, \mathrm{N}\}$ and $m \in\{\mathrm{Al}, \mathrm{Si}, \mathrm{O}, \mathrm{N}\}$ located at the $n$-th distance. $E_{0}$ denotes a part of the excess energy, which is assumed to be independent of the arrangement of the exchangeable cations. In solid solutions with coupled substitutions the $E_{0}$ is observed to vary with the composition (e.g. Vinograd et al., 2006), while the $J \mathrm{~s}$ appear to be approximately constant. The assumption of the independence of the $J \mathrm{~s}$ from the composition plays an important role in the studies of the solid solutions by reducing the number of the unknown variables. In this study we did not made such an assumption and calculated the $J \mathrm{~s}$, the chemical potentials, and the $E_{0}$ parameters for each of the two compositions separately. (An attempt to develop a uniform expansion for both $A$ and $B$ structures was made, but resulted in a worse fit). Knowing the energies, pair probabilities and site occupancies for $n$ structures allowed us to write a system of $n$ equations analogous to Eq. (1) and to solve this system for $J_{l m^{(n)}}, \mu_{i^{(k)}}$ and $E_{0}$ using the least squares method. The values of the fitted parameters are given in Table 5 and plotted in Figs. 4a and 4b. Note that only three chemical potentials are needed to define the site preferences of $\mathrm{Al}$ and $\mathrm{N}$. Since $\mathrm{Al}$ can be located either in the "single" or "ring" site, one chemical potential defined for the ring site is sufficient. For the similar reason two che- 
Table 5. The parameters of the cluster expansion.

\begin{tabular}{lrr}
\hline Parameter & \multicolumn{1}{c}{ Sialon $A$} & \multicolumn{1}{c}{ Sialon $B$} \\
\hline$\mu_{\mathrm{Al}(\text { ring) }}$ & 52.344015 & 48.598019 \\
$\mu_{\mathrm{N}(\text { star })}$ & -143.129171 & -139.476404 \\
$\mu_{\mathrm{N}(\text { layer })}$ & 9.741140 & 25.544804 \\
$E_{0}$ & 134.296874 & 136.757812 \\
\hline
\end{tabular}

mical potentials are needed to describe the relative affinity of $\mathrm{N}$ for the three different anion sites. The accuracy of the fit is illustrated in Fig. 5. The value of $E_{0}$ shows how large the enthalpy of a sialon compound would be if the dissimilar cation pairs had no advantage over the similar ones. The values of the chemical potentials (Table 5) show that there is a very strong intrinsic tendency for $\mathrm{N}$ to occupy the four-fold "star" site, and a weaker tendency to avoid the two-coordinated "layer" site. Al cations tend to avoid the "single" site. Another equally valid interpretation is that O strictly avoids the "star" and has a slight affinity for the "corner" site, while Si prefers to be located in the "single" site. The pair-wise interaction constants (Figs. 4a, 4b) manifest the tendency towards $\mathrm{Al} / \mathrm{Si}$ alternation, which is especially strong at the shortest distances. The same tendency is
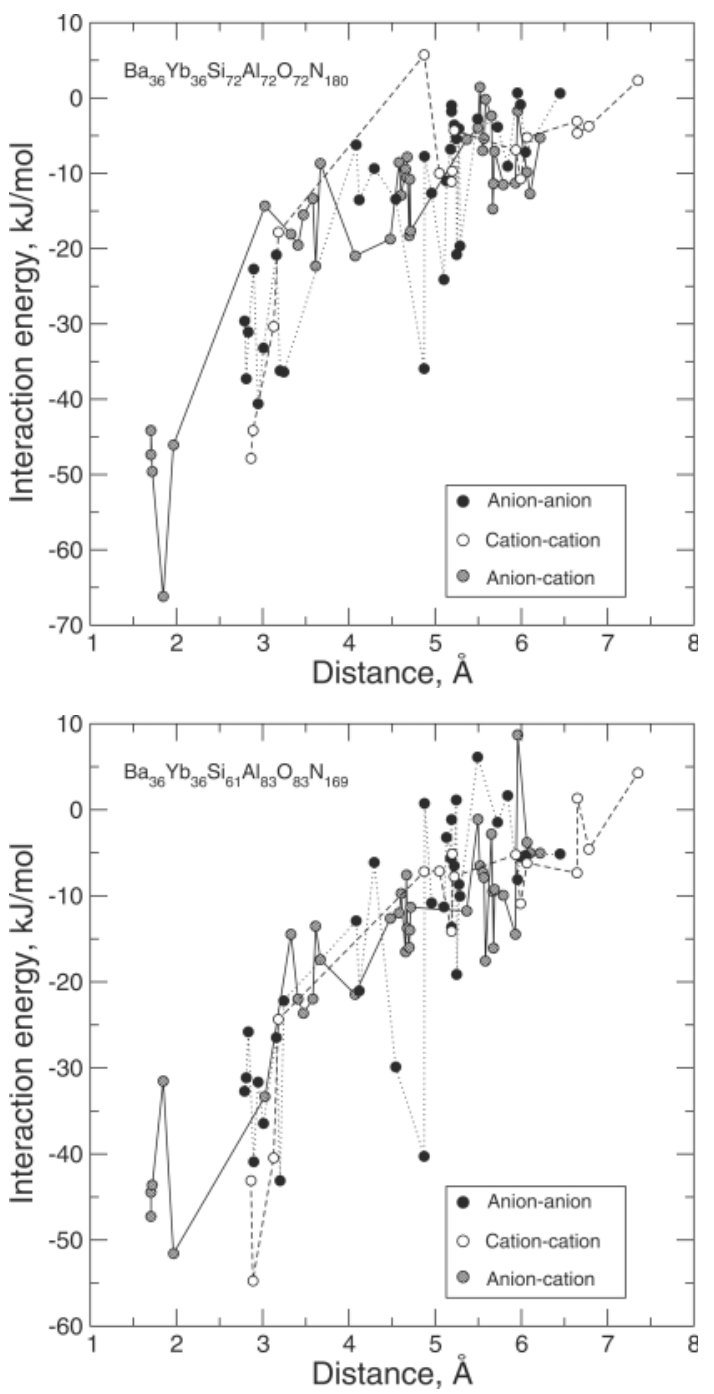

Fig. 4. Pair-wise interaction energies in the sialons $A$ (a) and $B$ (b) predicted with the cluster expansion method.

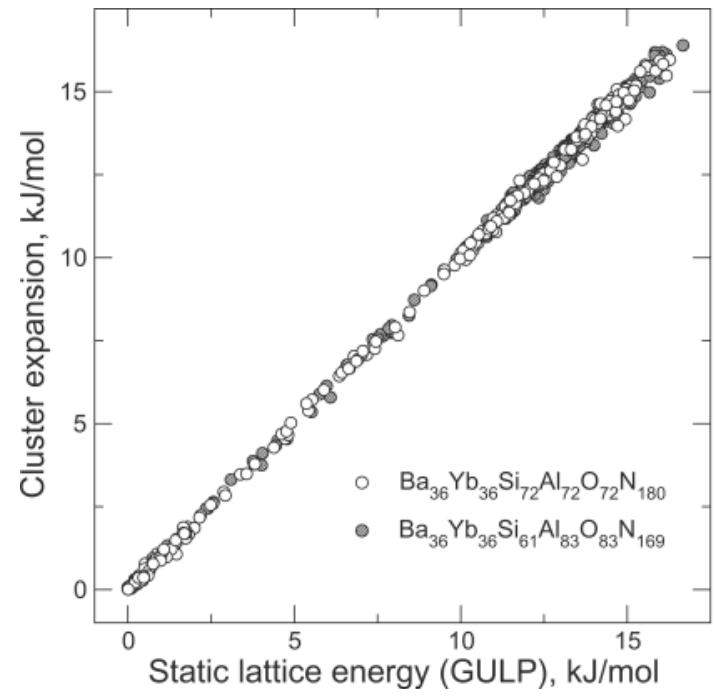

Fig. 5. Correlation between the original static lattice energies of randomly modified configurations and the energies calculated with the cluster expansion equation.

observed for the anion-anion pairs. This tendency becomes weaker with the increase in the nearest-neighbour distance. The cross-site anion-cation interactions define the enthalpy effect of the reaction $\mathrm{Al}-\mathrm{N}+\mathrm{Si}-\mathrm{O}=\mathrm{Al}-\mathrm{O}+\mathrm{Si}-\mathrm{N}$. The negative sign of these constants shows that $\mathrm{Al}-\mathrm{O}$ and $\mathrm{Si}-\mathrm{N}$ pairs are preferred over $\mathrm{Al}-\mathrm{N}$ and $\mathrm{Si}-\mathrm{O}$ pairs at all distances.

\section{Ground state analysis}

The cluster expansion results suggest that the configurations having large numbers of $\mathrm{Al}-\mathrm{Si}, \mathrm{O}-\mathrm{N}, \mathrm{Al}-\mathrm{O}$ and $\mathrm{Si}-\mathrm{N}$ pairs and large probabilities of finding $\mathrm{N}$ in the star sites, with $\mathrm{Si}$ in the single sites, should be more favourable at low temperatures. It is also clear that these tendencies cannot be satisfied for all pairs simultaneously due to the geometrical constraints. For example, the tendency for $\mathrm{Al} / \mathrm{Si}$ alternation cannot be fulfilled for all bonds of a cluster consisting of an uneven number of sites - the phenomenon often referred to as "frustration". Therefore, the exact nature of the lowest energy configuration is a compromise between the strength of the ordering interactions, the coordination numbers and numerous frustration constraints. It is impossible to simply guess the ground state structure. However, it is possible to find one of the best (in terms of the energy) structures using an algorithm consisting of a combination of the cluster expansion and Monte Carlo sampling. We have used a Monte Carlo algorithm (Metropolis et al., 1953) in which pairs of randomly chosen $\mathrm{Al}$ and $\mathrm{Si}$ and $\mathrm{O}$ and $\mathrm{N}$, atoms are repeatedly swapped producing a sequence of configurations. Each new configuration is accepted with the probability $\xi$, which is a function of the temperature and the energy difference between two successive configurations:

$$
\begin{aligned}
& \xi=1, \quad \Delta E<0 \\
& \xi=\exp (-\Delta E /(k T)), \quad \Delta E \geq 0
\end{aligned}
$$

The energy difference is calculated based on Eq. (1). Therefore, the cluster expansion stage always precedes the 
Monte Carlo stage. By setting the temperature high and gradually decreasing it, it is possible to find a state with the lowest energy through this process of simulated annealing. Note that the predicted low-energy structure would represent the true ground state only if the cluster expansion equation reproduces the static energy with zero error and if the annealing has sampled the lowest energy configuration. In practice one has to work with an equation that is about $99 \%$ accurate. When one calculates the static energy of the newly predicted structure directly with GULP and compares it with the value calculated with the cluster expansion, one usually finds that the two values differ quite severely. This means that the cluster expansion, if no special precautions are made, can predict a wrong ground state. However, the use of a simple feedback algorithm greatly improves the prediction quality of the expansion (Vinograd et al., 2006). At each step of this algorithm the new simulated structure is added to the set of previously considered configurations and the cluster expansion fit is repeated using the extended set. When this procedure is repeated in a cycle, the difference between static energy of the next configuration and its CE approximation rapidly decreases and the cluster expansion is forced to predict the correct ground state. This self-education procedure, consisting of 100 cycles, has been applied to sialons $A$ and $B$. The values of $J_{l m^{(n)}}, \mu_{i^{(k)}}$ and $E_{0}$ given in Table 5 and plotted in Figs. $4 \mathrm{a}$, and $4 \mathrm{~b}$ are, in fact, the results of this algorithm.

We should note that the presently adopted scheme for the ground state search can be further improved by using a cross validation score test (van de Walle and Ceder, 2002) instead of the current simple least squares test. Furthermore, genetic algorithms can be used for searching for the best cluster types within the cluster expansion (Hart et al., 2005). These algorithms are not implemented here for the following reasons. The self-education algorithm effectively applies the cross validation score ("leave-one-out") test to each new predicted low-energy structure. Since the number of these structures gradually increases in the pool of the tested structures, the accuracy of the cluster expansion approaches that of the cross validation score algorithm. Instead of using genetic algorithms in selecting the best cluster types, we select all possible pair clusters within the range of 1.6-7.5 $\AA$. The upper limit was chosen based on the criterion that the distance between any pair of neighbours remained less than one half of the supercell length along the vector connecting the neighbouring sites. This ensures that the images of atoms within the periodic boundary conditions setup do not affect the counting of dissimilar pairs. The use of many-body cluster terms appeared not to be necessary since good accuracy has been achieved for the cluster expansion based on the pair clusters only. This result might reflect the fact that the interactions in the ionic material are dominated by central forces.

\section{Large scale Monte Carlo simulations}

The derived interaction constants and Eq. (1) have been used to constrain the Monte Carlo simulation of the temperature dependent properties (the enthalpy of disorder and the crystallographic site occupancies) within a $4 \times 4 \times 4$

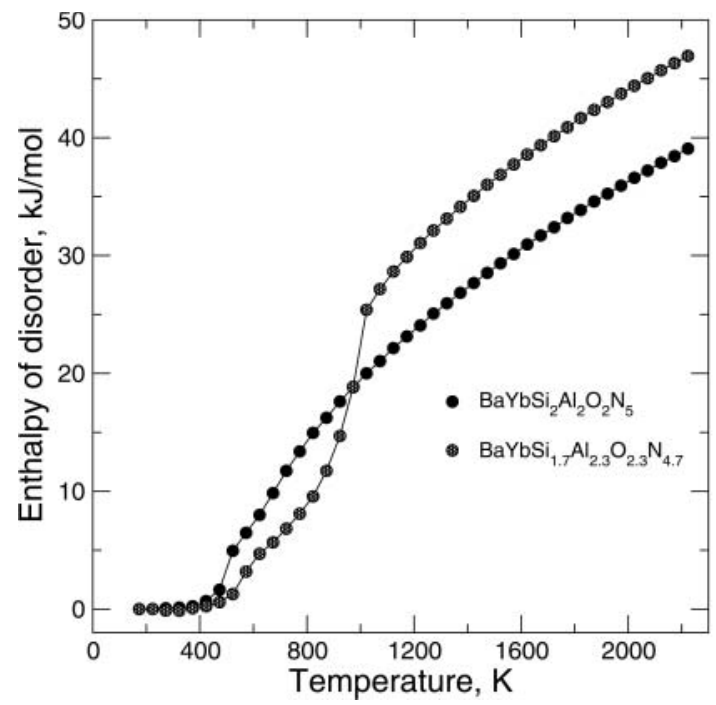

Fig. 6. Enthalpy of disorder in sialons $A$ and $B$ according to the results of Monte Carlo simulations.

supercell containing 3, 152 exchangeable sites. The simulations were performed within the temperature range of $173-2273 \mathrm{~K}$ with a step of $50 \mathrm{~K}$. The average properties
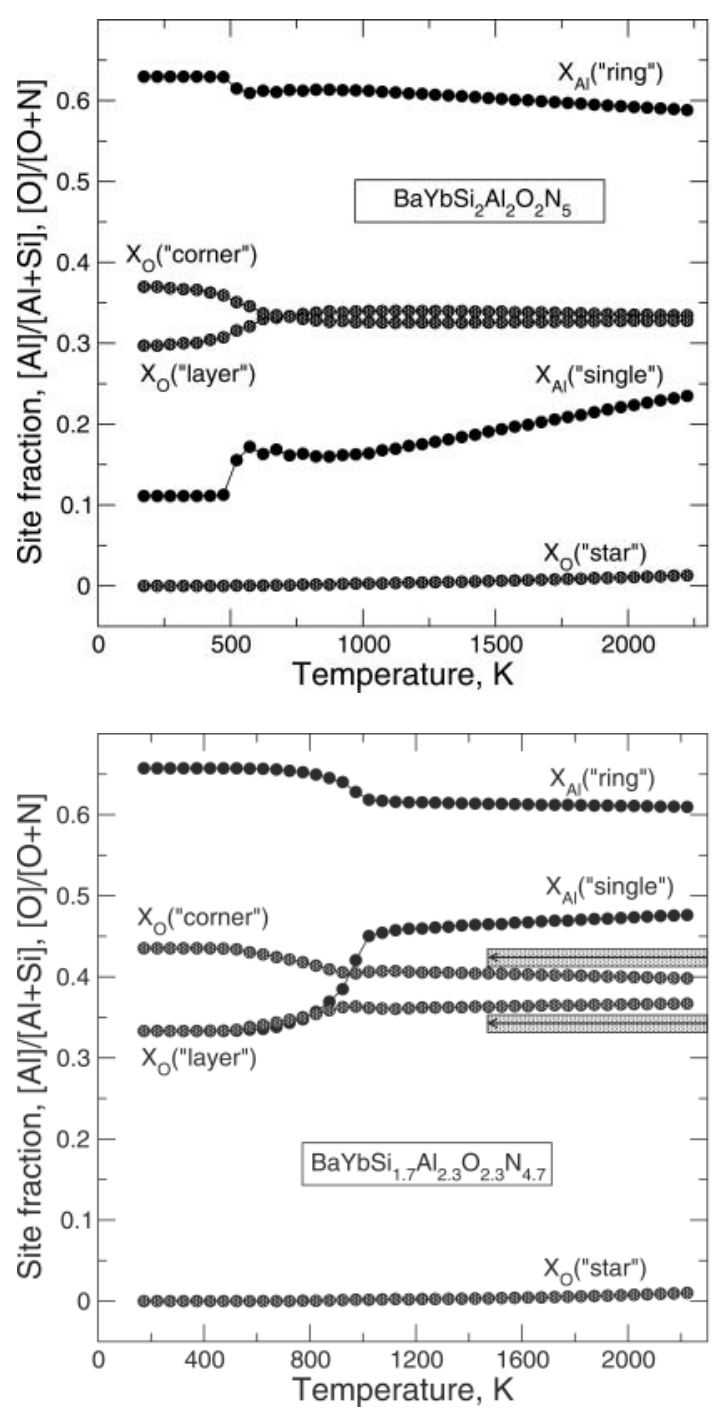

Fig. 7. Fractions of $\mathrm{Al}$ and $\mathrm{O}$ in crystallographically non-equivalent sites of sialons $A$ (a) and $B$ (b) as functions of the temperature. The rectangles show the neutron diffraction results. 


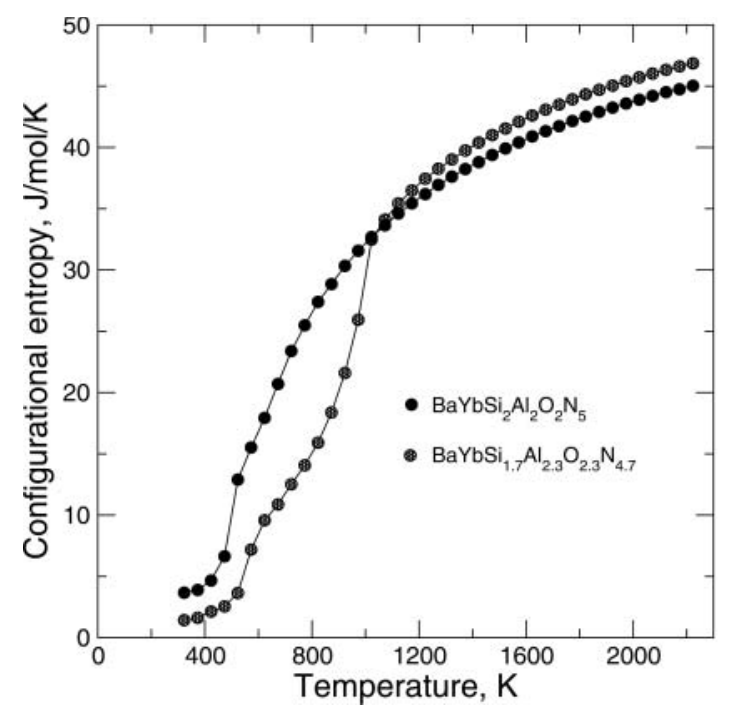

Fig. 8. The configurational entropy of the sialons $A$ and $B$ calculated with the method of thermodynamic integration.

were calculated using $10^{8}$ Monte Carlo steps. The average properties have been calculated by summing over the last half on the succession of states. The results of these calculations are shown in Fig. 6 and Figs. 7a, 7b. The enthalpy of disorder is found to gradually increase with the temperature, though a more rapid change is observed at $500 \mathrm{~K}$ (sialon $A$ ) and $1000 \mathrm{~K}$ (sialon $B$ ). The simulations show
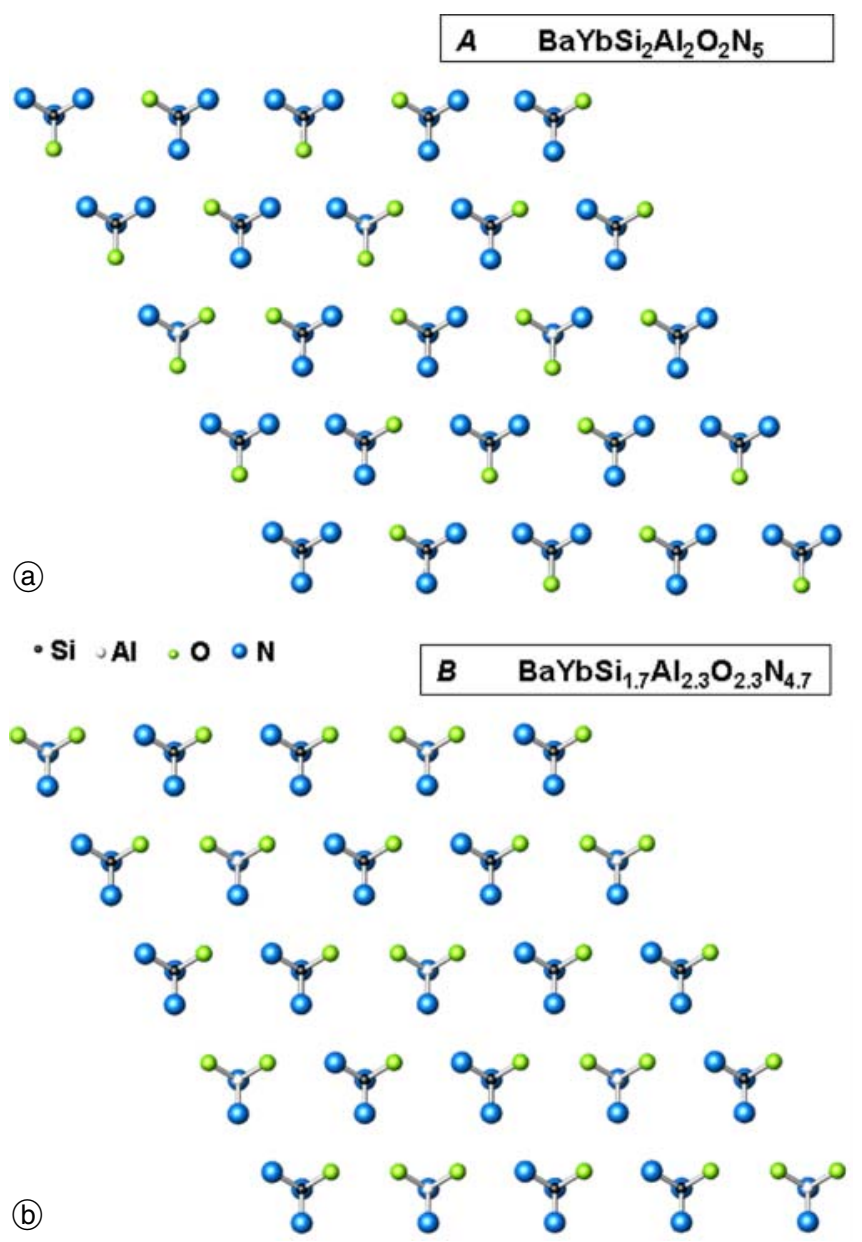

Fig. 9. Low-temperature configurations of sialons $A$ (a) and $B$ (b). The layer of the tetrahedral clusters centred on the "single" sites. that for either sample, at both low and high temperatures, $\mathrm{Al}$ atoms tend to enrich the "ring" site. At low temperatures, $\mathrm{O}$ shows affinity to corner sites, but at high temperatures the distribution between the two-coordinated "corner" and "layer" sites becomes approximately equal. The four-coordinated "star" site remains completely filled with $\mathrm{N}$ up to very high temperatures. The low energy configurations (Figs. 8a, b and Figs. 9a, b) show high degrees of shortrange order (SRO) and a strong or partial long-range order (LRO) depending on the composition.

\section{Thermodynamic integration}

Unlike the enthalpy of disorder, the configurational free energy cannot be directly calculated from a single Monte Carlo run. The calculation of the free energy requires an accurate knowledge of the frequencies of all energy states, including those that appear with very low probabilities. However, it has been shown (Myers et al., 1998; Myers, 1999; Warren et al., 2001) that the configurational free energy can be indirectly calculated from Monte Carlo averaged excess energies using the method of thermodynamic integration:

$$
F=F_{0}+\int_{0}^{\lambda}\langle E\rangle_{\lambda} \mathrm{d} \lambda
$$

In this equation, $F_{0}$ corresponds to the free energy of mixing of the system with zero ordering energy, which can be calculated theoretically:

$$
\begin{aligned}
F_{0}= & 4 R T\left(x_{\mathrm{Al}} \ln x_{\mathrm{Al}}+x_{\mathrm{Si}} \ln x_{\mathrm{Si}}\right) \\
& +7 R T\left(x_{\mathrm{N}} \ln x_{\mathrm{N}}+x_{\mathrm{O}} \ln x_{\mathrm{O}}\right)
\end{aligned}
$$

The integral describes the contribution to the free energy from the internal energy, $\langle E\rangle_{\lambda}$, when it changes from the state of complete disorder $(\lambda=0)$ to the state of equilibrium order $(\lambda=1)$. $\lambda$ should not be confused with the equilibrium order parameter, which is a function of temperature. $\lambda$ describes non-equilibrium disorder, which is artificially introduced at any given temperature. To calculate $\langle E\rangle_{\lambda}$ for a state with an intermediate degree of order defined by certain value of $\lambda, 0<\lambda<1$, one scales the $J_{\mathrm{s}}$ and the chemical potentials:

$$
J_{l m^{(n)}}^{\lambda}=\lambda J_{l m^{(n)}}, \quad \mu_{i^{(k)}}^{\lambda}=\lambda \mu_{i^{(k)}}
$$

in order to simulate a Boltzmann distribution constrained with $J_{l m^{(n)}}^{\lambda}$ and $\mu_{i^{(k)}}^{\lambda}$. Effectively, the scaling implies that the probabilities of microstates become more random than in the non-scaled case. $\langle E\rangle_{\lambda}$ is then calculated using Eq. (1) with nominal (not scaled) values of $J_{l m^{(n)}}^{\lambda}$ and $\mu_{i^{(k)}}^{\lambda}$ by taking a simple average over a sufficient number of the equilibrated configurations. The scaling thus makes the distribution more random, but does not affect the strength of the interactions. In our simulations, $\lambda$ was gradually increased from 0 to 1 with a step size of 0.04 . The integral was calculated using Simpson's method. The configurational entropy was calculated with the equation;

$$
S=(F-\langle E\rangle) / T
$$

where $\langle E\rangle$ is the average excess internal energy (or enthalpy) calculated with $\lambda=1$. Figure 8 shows the config- 
urational entropy in the interval of $323-2273 \mathrm{~K}$. A rapid increase in order occurs at $500 \mathrm{~K}$ for sialon $A$ and at $1000 \mathrm{~K}$ for sialon- $B$. Even at $2000 \mathrm{~K}$ the configurational entropy remains significantly below the ideal mixing limit reflecting high degree of SRO.

\section{Discussion and conclusions}

The present simulations agree with the Rietveld refinement results in three aspects. First of all, both the neutron diffraction results and the simulations suggest that oxygen does not enter the four-fold coordinated "star" site in a measurable amount. This behaviour is consistent with the $2^{\text {nd }}$ rule of Pauling (e.g. Morgan, 1986). The large valence/bond sum of the four $\mathrm{Al} / \mathrm{Si}$ cations is much better satisfied with $\mathrm{N}^{3-}$ rather than with $\mathrm{O}^{2-}$. Secondly, the simulations support the unconstrained Rietveld refinement result, which suggests significant affinity of $\mathrm{Si}$ for the "single" site. Thirdly, the prediction of the slightly higher concentration of oxygen in the two-fold "corner" site is also consistent with the experiment. The last consistency might not be significant, however, due to large experimental errors and limitations of the simulation methods. $\mathrm{Ab}$ initio calculations on $\mathrm{O}$-doped $\mathrm{BaYbSi}_{4} \mathrm{~N}_{7}$ nitridosilicates show an approximate equal affinity of the oxygen to "corner" and "layer" sites (Wilson et al., 2007).

The simulations not only make it feasible to predict the site occupancies, but also to explain why a certain site is preferable for $\mathrm{Al}$ or $\mathrm{O}$. The preference of $\mathrm{Al}$ for the "ring" sites is consistent with the advantage of maximising the number of $\left[\mathrm{SiAl}_{2} \mathrm{ON}_{2}\right]^{2+}$ rings. This tendency is preserved even at the synthesis temperature. The ordered arrangement of cations and anions within these rings maximises the number of the nearest-neighbour $\mathrm{Al}-\mathrm{O}$ and $\mathrm{N}-\mathrm{Si}$ contacts and minimises the valence/bond imbalance both for the anions and cations. It is important that the ordered arrangement of the rings allows complete avoidance of the $\mathrm{Al}-\mathrm{N}-\mathrm{Al}$ contacts, in which $\mathrm{N}$ is strongly underbonded. The preference for the local $\left[\mathrm{SiAl}_{2} \mathrm{ON}_{2}\right]^{2+}$ configuration requires migration of the excess $\mathrm{O}$ from the "layer" to the "corner" sites.

Both sialons $A$ and $B$ show breaks in the enthalpy and entropy curves, which could be attributed to SRO/LRO transitions. However, the configurational entropy does not vanish in the low temperature limit (Fig. 10). This indicates that the $\mathrm{Al} / \mathrm{Si}$ and $\mathrm{O} / \mathrm{N}$ ratios of both sialon $A$ and $B$ deviate from the composition at which full LRO is possible. Sialon $B$ shows the strongest ordering. Figure $7 \mathrm{~b}$ shows that the molar fraction of $\mathrm{Al}$ in the "single" site in sialon $B$ is equal to $1 / 3$. The type of LRO that favours this distribution can be understood by inspecting Figs. $9 \mathrm{~b}$ and 10b. Figures $9 \mathrm{a}$ and $10 \mathrm{a}$, which correspond to sialon $A$, show less regular cation and anion distributions suggesting that the composition of the sialon $A$ is less favourable for the development of the LRO. The low temperature distribution favours only two types of the tetrahedral clusters, $\left[\mathrm{SiN}_{3} \mathrm{O}\right]^{7-}$ and $\left[\mathrm{AlN}_{2} \mathrm{O}_{2}\right]^{7-}$. In sialon $B$, the Al- and Sicentred tetrahedra are distributed regularly over the sites of a triangular lattice. The equal charge of these clusters suggests that $\mathrm{Al} / \mathrm{Si}$ and $\mathrm{N} / \mathrm{O}$ distributions effectively cooperate in an attempt to preserve local charge balance on the

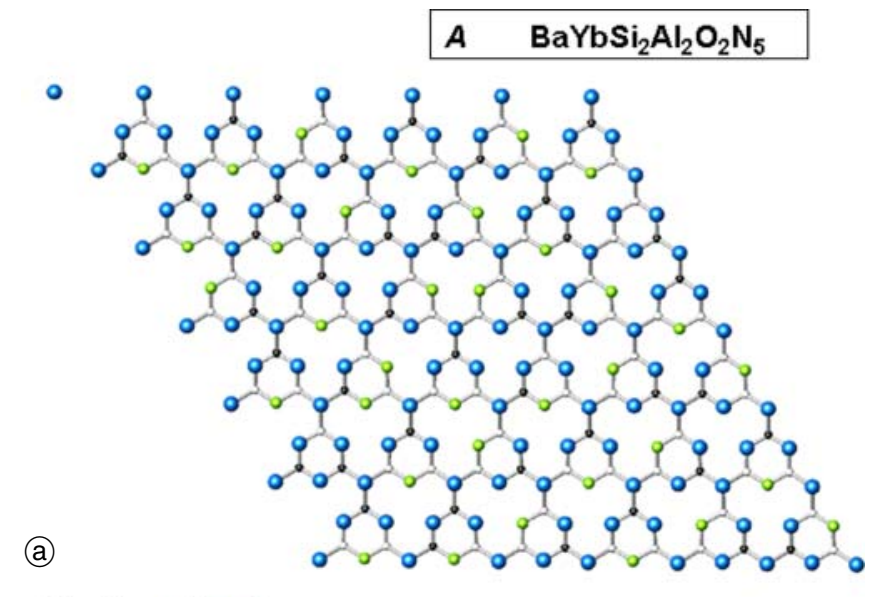

- Si Al $\circ$ O $N$

B $\quad \mathrm{BaYbSi}_{1.7} \mathrm{Al}_{2.3} \mathrm{O}_{2.3} \mathrm{~N}_{4.7}$

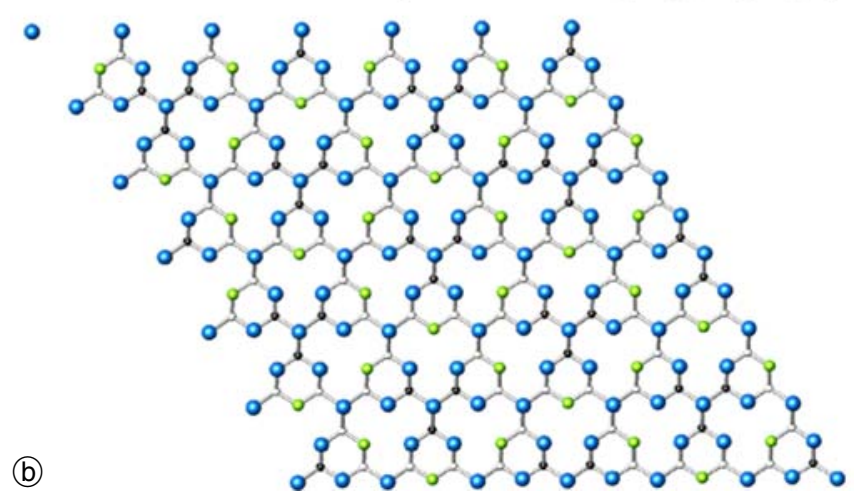

Fig. 10. Low-temperature configurations of sialons $A(\mathbf{a})$ and $B(\mathbf{b})$. The layer built of the "ring" tetrahedra.

scale of the very small clusters. Figure 11a illustrates this tendency for sialon $B$ on a more quantitative level. The transition at $1000 \mathrm{~K}$ corresponds to a rapid increase in the frequencies of occurrence of $\left[\mathrm{SiN}_{3} \mathrm{O}\right]^{7-}$ and $\left[\mathrm{AlN}_{2} \mathrm{O}_{2}\right]^{7-}$ clusters centred on the single sites. Figure $11 \mathrm{~b}$ quantifies the frequencies of the tetrahedral clusters around the "ring" sites and reveals a more complicated tendency. The ordered state is built with clusters of four types; $\left[\mathrm{SiN}_{3} \mathrm{O}\right]^{7-}$, $\left[\mathrm{AlN}_{2} \mathrm{O}_{2}\right]^{7-}, \quad\left[\mathrm{AlN}_{3} \mathrm{O}\right]^{8-}$ and $\left[\mathrm{SiN}_{4}\right]^{8-}$. The ordering is apparently a two-stage process. During the first stage, below $1000 \mathrm{~K}$, about $2 / 3$ of $\mathrm{Si}$ and $2 / 3$ of $\mathrm{Al}$ sites prefer $\left[\mathrm{SiN}_{3} \mathrm{O}\right]^{7-}$ and $\left[\mathrm{AlN}_{3} \mathrm{O}\right]^{8-}$ configurations and the other ${ }^{1 / 3}$ of $\mathrm{Si}$ and $\mathrm{Al}$ sites choose $\left[\mathrm{SiN}_{4}\right]^{8-}$ and $\left[\mathrm{AlN}_{2} \mathrm{O}_{2}\right]^{7-}$ configurations. At the second step, at about $500 \mathrm{~K}$, the proportion further changes in favour of $\left[\mathrm{SiN}_{3} \mathrm{O}\right]^{7-}$ and $\left[\mathrm{AlN}_{2} \mathrm{O}_{2}\right]^{7-}$ configurations (Fig. 11a). The rapid increase in concentration of these clusters is apparently correlated with the long-range ordering of $\left[\mathrm{AlN}_{2} \mathrm{O}_{2}\right]^{7-}$ units over the $1 / 3$ of the sites of the triangular lattice formed by the "single" tetrahedral units. The low temperature of this transition suggests that the interaction energy between $\left[\mathrm{AlN}_{2} \mathrm{O}_{2}\right]^{7-}$ and $\left[\mathrm{SiN}_{3} \mathrm{O}\right]^{7-}$ units is small. Particularly interesting is the variation in the fractions of the 6-membered ring clusters formed by the three corner-sharing "ring" tetrahedra (Fig. 12). The transition at $1000 \mathrm{~K}$ in sialon $B$ corresponds to an abrupt increase in the fraction of $\left[\mathrm{SiAl}_{2} \mathrm{ON}_{2}\right]^{2+}$ rings. The tendency of sialons $A$ and $B$ to form $\left[\mathrm{SiAl}_{2} \mathrm{ON}_{2}\right]^{2+}$ rings suggests that $2 / 3$ of $\mathrm{Al}$ in the "ring" sites should be the most favourable for the development of LRO. On the 

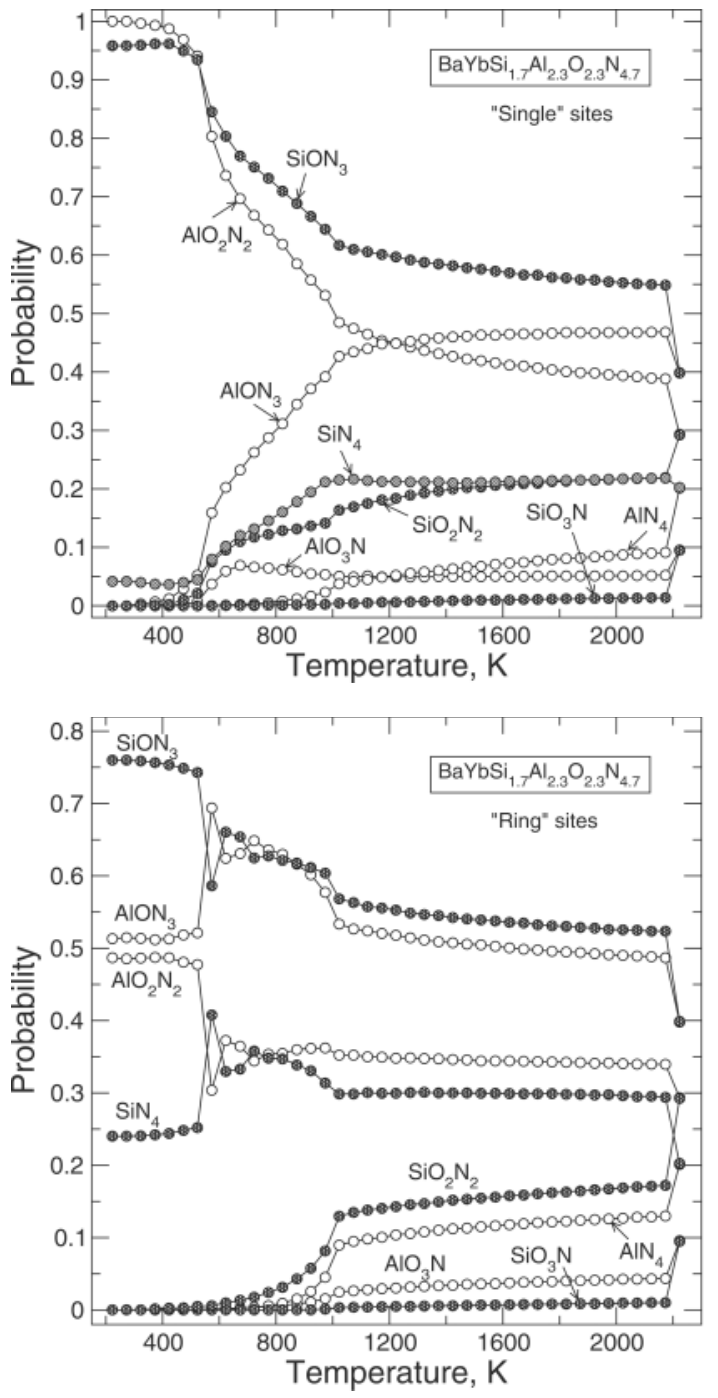

Fig. 11. The probabilities (frequencies of occurrence) of the tetrahedral clusters centred on the "ring" (a) and "single" (b) sites as functions of the temperature. The probabilities are calculated separately for Al- and Si-centred tetrahedra, which are distinguished by white and grey circles, respectively. The last row of the points at the hightemperature side of the graph shows the frequencies in the limit of the complete disorder.

other hand, the maximisation of $\left[\mathrm{SiN}_{3} \mathrm{O}\right]^{7-}$ and $\left[\mathrm{AlN}_{3} \mathrm{O}\right]^{8-}$ clusters centred with "single" sites requires their ordered arrangement, which in the case of the triangular lattice is best satisfied with $1 / 3$ of $\mathrm{Al}$ in the "single" site. Thus we suggest that the most favourable composition for detecting LRO experimentally should be $x=1 / 3$. Sialon $B$ is closer to this "ideal" composition and, consequently, the order/ disorder transition occurs at a higher temperature. Above the order/disorder transition only SRO is present. This local ordering is seen in the predominance of $\left[\mathrm{SiAl}_{2} \mathrm{ON}_{2}\right]^{2+}$ rings (Fig. 12) and $\left[\mathrm{SiN}_{3} \mathrm{O}\right]^{7-},\left[\mathrm{AlN}_{2} \mathrm{O}_{2}\right]^{7-},\left[\mathrm{AlN}_{3} \mathrm{O}\right]^{8-}$ and $\left[\mathrm{SiN}_{4}\right]^{8-}$ tetrahedra both centred on "single" and "ring" sites (Figs. 11a, b).

The simulation results thus suggest that $\mathrm{Al} / \mathrm{Si}$ and $\mathrm{O} / \mathrm{N}$ are distributed very unevenly between the non-equivalent sites. This non-equivalence is mainly a consequence of short-range ordering (the preference in formation of the $\left[\mathrm{SiAl}_{2} \mathrm{ON}_{2}\right]^{2+}$ rings). It is also likely that the site occupancies further split at low temperatures due to the develop-

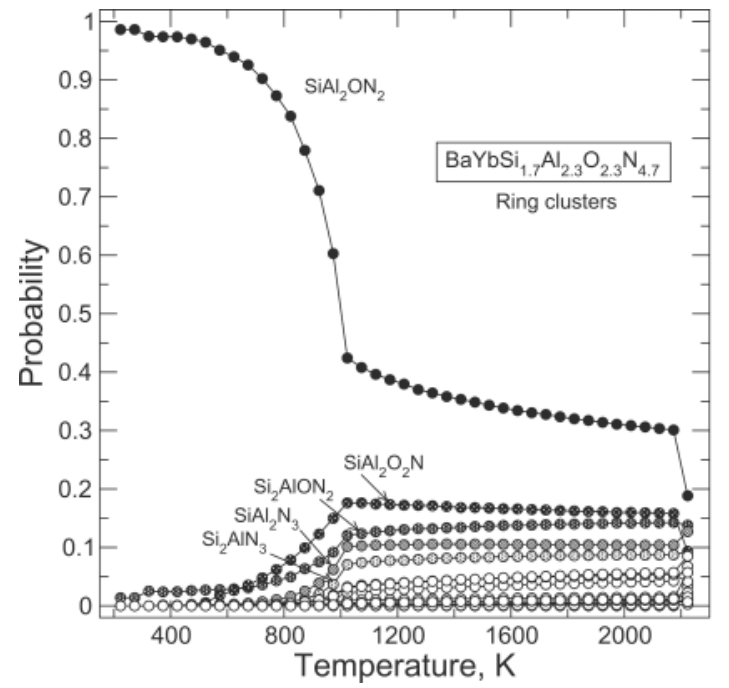

Fig. 12. Probabilities of 6-membered rings formed by the three corner-shared "ring" tetrahedra. The last row of the points at the hightemperature side of the graph shows the frequencies in the limit of complete disorder.

ment of long-range ordering. The simulations suggest that the LRO sets in first within the layers formed by the "ring" sites and then, at a much lower temperature, within the layers made of the "single" sites. The strong dependence of the effects of ordering on the composition suggests that slight compositional changes might cause rapid changes in certain thermodynamic and physical properties of the sialons. This suggestion should be tested in further experimental and simulation studies.

Acknowledgments. The authors gratefully acknowledge financial support from the Deutsche Forschungsgemeinschaft (DFG) (Grants WI 1232/14-2, WI 1232/17-2, SCHN 377/9-1, SCHN 377/9-2). JDG would like to thank the Government of Western Australia for funding through a Premier's Research Fellowship. Thanks are due to Robert Kraut for help with the sample preparation and Dr. Ron Smith (local support at the POLARIS beamline at ISIS) for help with the neutron diffraction measurements. The calculations were performed at the Center for Scientific Computing at the University of Frankfurt.

\section{References}

Bass, J. D.: Elasticity of Minerals, Glasses, and Melts. In: (Ahrens Th. J., Ed.): Mineral Physics \& Crystallography. A Handbook of Physical Constants. AGU Reference Shelf Ser 2. Am. Geophys. Union, (1995) pp. 45-63.

Becker, U.; Fernandez-Gonzalez, A.; Prieto, M.; Harrison, R.; Putnis, A.: Direct calculation of thermodynamic properties of the barite/celestite solid solution from molecular principles. Phys. Chem. Miner. 27 (2000) 291-300.

Becker, U.; Pollok, K.: Molecular simulations of interfacial and thermodynamic mixing properties of the grossular-andradite garnets. Phys. Chem. Miner. 29 (2002) 52-64.

Blase, W.; Cordier, G.; Ludwig, M.; Kniep, R.: $\mathrm{Sr}_{3}\left(\mathrm{Al}_{2} \mathrm{~N}_{4}\right)$ : ein Nitridoaluminat mit gewellten Tetraederketten $1(\operatorname{AlN} 4 / 2(3-))$. Z. Naturforsch. B. Anorganische Chemie, Organische Chemie. 49 (1994) 501-505.

Benna, P.; Bruno, E.: Single-crystal in situ high-temperature structural investigation on strontium feldspar. Am. Mineral. 86 (2001) 690696.

Bosenick, A.; Dove, M. T.; Myers, E. R.; Palin, E. J.; Sainz-Diaz, C. I.; Guiton, B. S.; Warren, M. C.; Craig, M. S.: Computational methods for the study of energies of cation distributions: applications to cation-ordering phase transitions and solid solutions. Mineral. Mag. 65 (2001) 193-219. 
Bush, T. S.; Gale, J. D.; Catlow, C. R. A; Battle, P. D.: Self-consistent interatomic potentials for the simulation of binary and ternary oxides. J. Mater Chem. 4 (1994) 831-837.

Chernaya, T. S.; Muradyan, L. A.; Sarin, V. A.; Uyukin, E. M.; Bagdasarov, Kh. S.; Simonov, V. I.: Neutron-diffraction structural investigation of single crystals of $\mathrm{Y}_{3} \mathrm{Al}_{5} \mathrm{O}_{12}: \mathrm{Nd}\left(3^{+}\right)$Soviet Phys. Crystallogr. 34(5) (1989) 778-780.

Ching, W. Y.; Ouyang. L.; Gale, J. D.: Full ab initio geometry optimisation of all known crystalline phases of $\mathrm{Si}_{3} \mathrm{~N}_{4}$, Phys. Rev. B61 (2000) 8696-8700.

Clark, S. J.; Segall, M. D.; Pickard C. J.; Hasnip P. J.; Probert, M. J.; Refson, K.; Payne, M. C.: First principles methods using CASTEP. Z. Kristallogr. 220 (2005) 567-570.

Connolly, J. W. D.; Williams, A. R.: Density-functional theory applied to phase transformations in transition-metall alloys. Phys. Rev. B27 (1983) 5169-5172.

Doenni, A.; Fischer, P.; Furrer, A.; Bacsa, W.; Wachter, P.: F.c.c. type-III antiferromagnetism in YbN. Z. Phys. B80 (1984) 269-274.

Fert, A.: Structure de quelques oxydes de terres rares. Bull. Soc. Francaise Mineral. Cristallogr. 85 (1962) 267-270.

Gale, J. D.: Empirical potential derivation for ionic materials. Phil. Mag. B73 (1996) 3-19.

Gale, J. D.: GULP - a computer program for symmetry adapted simulations of solids. J Chem Soc: Faraday Trans. 93 (1997) 629-637.

Gale, J. D.; Rohl, A. L.: The General Utility Lattice Program (GULP). Mol. Simul. 29 (2003) 291-341.

Gillott, L.; Cowlam, N.; Bacon, G. E.: A neutron diffraction investigation of some beta-sialons. J. Mater. Sci. 16 (1981) 2263-2268.

Goniakowski, J.; Holdender, J. M.; Kantarovich, L. N.; Gillan, M. J.; White, J. A.: Influence of gradient corrections on the bulk and surface properties of $\mathrm{TiO}_{2}$ and $\mathrm{SnO}_{2}$. Phys. Rev. B53 (1996) 957-960.

Hamman, D. R.: Generalized gradient theory for silica phase transitions. Phys. Rev. Lett. 76 (1996) 660-663.

Hampshire, S.: Materials Science and Technology. (R. W. Cahn, P. Haasen, E. J. Kramer, Eds.) VCH, Weinheim 1994, Vol. 11, p. 119.

Hart, G. L. W., Blum, V., Walorski, M. J., Zunger, A.: Evolutionary Approach for Determination of First-Principles Hamiltonians. Nature Materials (Letters) 4 (2005) 391-394.

Heiba, Z. K.; Akin, Y.; Sigmund, W.; Hascicek, Y. S.: X-ray structure and microstructure determination of the mixed sesquioxides $\left(\mathrm{Eu}_{1-x} \mathrm{Yb}_{x}\right)_{2} \mathrm{O}_{3}$ prepared by a sol-gel process. J. Appl. Crystallogr. 36 (2003) 1411-1416.

Hohenberg, P.; Kohn, W.: Inhomogeneous electron gas. Phys. Rev. B136 (1964) 864-B871.

Holleck, H.; Smailos, E.: Mischnitride von Thorium mit Seltenen Erden. J. Nucl. Materials 91 (1980) 237-239.

Huppertz, H.; Schnick, W.: Synthese, Kristallstruktur und Eigenschaften der Nitridosilicate $\mathrm{SrYbSi}_{4} \mathrm{~N}_{7}$ und $\mathrm{BaYbSi}_{4} \mathrm{~N}_{7}$. Z. Anorg. Allg. Chem. 623 (1997) 212-217.

Huppertz, H.; Schnick, W.: $\mathrm{BaYbSi}_{4} \mathrm{~N}_{7}-$ Surprising Structural Possibilities in Nitridosilicates. Angew. Chem. Int. Ed. Engl. 35 (1996) 1983-1984.

Huppertz, H.; Schnick, W.: $\mathrm{Eu}_{2} \mathrm{Si}_{5} \mathrm{~N}_{8}$ and $\mathrm{EuYbSi}_{4} \mathrm{~N}_{7}-$ The First Nitridosilicates with a Divalent Rare Earth. Acta Crystallogr. C53 (1997) $1751-1753$.

Jones, R. O.; Gunnarsson, O.: The density functional formalism, its applications and prospects. Rev. Mod. Phys. 61 (1989) 689-746.

Juarez-Arellano, E. A.; Friedrich, A.; Knorr, K.; Lieb, A.; Winkler, B.; Amboage, M.; Hanfland M.; Schnick, W.: Compressibility of the

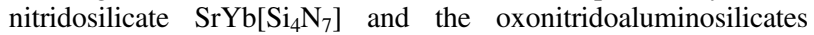
$M \mathrm{Yb}\left[\mathrm{Si}_{4-x} \mathrm{Al}_{x} \mathrm{O}_{x} \mathrm{~N}_{7-x}\right](x=2 ; M=\mathrm{Sr}, \mathrm{Ba})$. Acta Cryst. B62 (2006) 424-430.

Khvatinskaya, D. Ya.; Em, V. T.; Loryan, V. E.; Smirnov, K. L.: Neutronographic study of beta'-sialon structure. Izvestiya Akademii Nauk SSSR, Neorganicheskie Materialy. 27 (1991) 2124-2126.

Kohn, W.; Sham, L. J.: Self-consistent equations including exchange and correlation effects. Phys. Rev. 140 (1965) A1133-A1138.

Kresse, G.; Hafner, J.: Norm-conserving and ultrasoft pseudopotentials for first-row and transition elements. J. Phys: Condens Matt. 6 (1994) 8245-8257.

Kroll, P.; Milko, M.: Theoretical investigation of the solid state reaction of silicon nitride and silicon dioxide forming silicon oxynitride $\left(\mathrm{Si}_{2} \mathrm{~N}_{2} \mathrm{O}\right)$ under pressure. Z. Anorg. Allg. Chem. 629 (2003) $1737-1750$.
Kryachko, E. S.; Ludena, E. V.: Energy density functional theory of many-electron systems. In: Understanding Chemical Reactivity, 4, Kluwer Academic Publishers, Dordrecht. (1990).

Lauterbach, R.; Schnick, W.: Synthese, Kristallstruktur und Eigenschaften eines neuen Sialons $-\mathrm{SrSiAl}_{2} \mathrm{O}_{3} \mathrm{~N}_{2}$. Z. Anorg. Allg. Chem. 624 (1998) 1154-1158.

Lauterbach, R.; Schnick, W.: High-temperature synthesis and singlecrystal X-ray structure determination of $\mathrm{Sr}_{10} \mathrm{Sm}_{6} \mathrm{Si}_{30} \mathrm{Al}_{6} \mathrm{O}_{7} \mathrm{~N}_{54}-\mathrm{a}$ layered sialon with an ordered distribution of $\mathrm{Si}, \mathrm{Al}, \mathrm{O}$, and $\mathrm{N}$. Solid State Sci. 2 (2000) 463-472.

Lauterbach, R.; Schnick, W.: $\mathrm{Nd}_{3} \mathrm{Si}_{5} \mathrm{AlON}_{10}$ - Synthese, Kristallstruktur und Eigenschaften eines Sialons im $\mathrm{La}_{3} \mathrm{Si}_{6} \mathrm{~N}_{11}$-Strukturtyp. Z. Anorg. Allg. Chem. 626 (2000) 56-61.

Lauterbach, R.; Irran, E.; Henry, P. F.; Weller, M. T.; Schnick, W.: High-temperature synthesis, single-crystal $\mathrm{X}$-ray and neutron powder diffraction, and materials properties of $\mathrm{Sr}_{3} \mathrm{Ln}_{10} \mathrm{Si}_{18} \mathrm{Al}_{12} \mathrm{O}_{18} \mathrm{~N}_{36}$ $(\mathrm{Ln}=\mathrm{Ce}, \mathrm{Pr}, \mathrm{Nd})-$ novel sialons with an ordered distribution of $\mathrm{Si}, \mathrm{Al}, \mathrm{O}$, and N. J. Mater. Chem. 10 (2000) 1357-1364.

Leung, T. C.; Chan, C. T.; Harmon, B. N.: Ground-state properties of $\mathrm{Fe}, \mathrm{Co}, \mathrm{Ni}$ and their monoxides: results of the generalized gradient approximation. Phys. Rev. B44 (1991) 2923-2927.

Lewis, G. V.; Catlow, C. R. A.: Potential models for ionic oxides. J. Phys. C: Solid State Phys. 18 (1985) 1149-1161.

Lieb, A.; Kechele, J. A.; Kraut, R.; Schnick, W.: The sialons $M \mathrm{Ln}\left[\mathrm{Si}_{4-x} \mathrm{Al}_{x} \mathrm{O}_{x} \mathrm{~N}_{7-x}\right]$ with $M=\mathrm{Eu}, \mathrm{Sr}, \mathrm{Ba}$ and $\mathrm{Ln}=\mathrm{Ho}-\mathrm{Yb}-$ twelve substitution variants with the $\mathrm{MYb}\left[\mathrm{Si}_{4} \mathrm{~N}_{7}\right]$ structure type. Z. Anorg. Allg. Chem. 633 (2007) 166-171.

Lieb, A.; Schnick, W.: $\mathrm{BaSm}_{5}\left[\mathrm{Si}_{9} \mathrm{Al}_{3} \mathrm{~N}_{20}\right] \mathrm{O}$ - a nitridoaluminosilicate oxide with a new structure type composed of "star-shaped" $\left[\mathrm{N}^{[4]}\left((\mathrm{Si}, \mathrm{Al}) \mathrm{N}_{3}\right)_{4}\right]$ units as secondary building units. Solid State Sci. 8 (2006) 185-191.

Morgan, P. E. D.: Pauling's second crystal rule for nitrogen-substituted crystal structures. J. Mater. Sci. 21 (1986) 4305-4309.

Myers, E. R.: Al/Si ordering in silicate minerals. Ph.D. thesis, Univ. of Cambridge. (1999).

Myers, E. R.; Heine, V.; Dove, M. T.: Some consequences of Al/Al avoidance in the ordering of $\mathrm{Al} / \mathrm{Si}$ tetrahedral framework structures. Phys. Chem. Minerals. 25 (1998) 457-464.

Metropolis, N. I.; Rosenbluth, A. W.; Rosenbluth, M. N.; Teller, A. N.; Teller, E.: Equation of state calculations by fast computing machines. J. Chem. Phys. 21 (1953) 1087-1092.

Nordberg, L.-O.; Nygren, M.; Käll, P.-O.; Shen, Z.: Stability and Oxidation Properties of RE- $\alpha$-Sialon Ceramics $(\mathrm{RE}=\mathrm{Y}, \mathrm{Nd}, \mathrm{Sm}$, Yb). J. Amer. Ceram. Soc. 81 (1998) 1461-1470.

Novak, G. A.; Gibbs, G. V.: The crystal chemistry of the silicate garnets. Am. Mineral. 56 (1971) 791-823.

Palko, J. W.; Kriven, W. M.; Sinogeikin, S. V.; Bass, J. D.; Sayir, A.: Elastic constants of yttria $\left(\mathrm{Y}_{2} \mathrm{O}_{3}\right)$ monocrystals to high temperatures J. Appl. Phys. 89 (2001) 7791-7796.

Parr, R. G.; Yang, W.: Density-functional theory of atoms and molecules. (1989) Oxford University Press.

Patel, A.; Price, G. D.; Mendelsson, M. J.: A computer-simulation approach to modeling the structure, thermodynamics and oxygen isotope equilibria of silicates. Phys. Chem. Minerals. 17 (1991) 690-699.

Perdew, J. P.; Burke, K.; Ernzerhof, M.: Generalized gradient approximation made simple. Phys. Rev. Lett. 77 (1996) 3865-3868.

Putnis, A.; Salje, E.; Redfern, S. A. T.; Fyfe, C.; Stroble, H.: Structural states of $\mathrm{Mg}$-cordierite I: Order parameters from synchrotron X-ray and NMR data. Phys. Chem. Minerals. 14 (1987) 446-456.

Sanchez, J. M.; Ducastelle, F.; Gratias, D.: Generalized cluster description of multicomponent systems. Physica A128 (1984) 334-350.

Schlieper, T.; Milius, W.; Schnick, W.: Nirido-silicate. II: Hochtemperatur-Synthesen und Kristallstrukturen von $\mathrm{Sr}_{2} \mathrm{Si}_{5} \mathrm{~N}_{8}$ und $\mathrm{Ba}_{2} \mathrm{Si}_{5} \mathrm{~N}_{8}$. Z. Anorg. Allg. Chem. 621 (1995) 1380-1384.

Schneider, J.; Frey, F.; Johnson, N.; Laschke, K.: Structure refinements of beta- $\mathrm{Si}_{3} \mathrm{~N}_{4}$ at temperatures up to $1360 \mathrm{C}$ by X-ray powder investigation. Z. Kristallogr. 209 (1994) 328-333.

Schnick, W.; Huppertz, H.; Lauterbach, R.: High temperature syntheses of novel nitrido- and oxonitrido-silicates and sialons using $r f$ furnaces. J. Mater. Chem. 9 (1999) 289-296.

Srinivasa, S. R.; Jorgensen, J. D.; Worton, T. G.; Bayerlein, R. A.; Billy, M.: High-pressure neutron diffraction study of $\mathrm{Si}_{2} \mathrm{~N}_{2} \mathrm{O}$. J. Appl. Crystallogr. 10 (1977) 167-171. 
Thayaparam, S.; Heine, V.; Dove, M. T.; Hammonds, K. T.: A computational study of $\mathrm{Al} / \mathrm{Si}$ ordering in cordierite. Phys. Chem. Minerals. 23 (1996) 127-139.

Thompson, D. P.; Mandal, H.: 21st Century Ceramics. The Institute of Materials, London (1996).

Toraya, H.: Crystal structure refinement of alpha- $\left(\mathrm{Si}_{3} \mathrm{~N}_{4}\right)$ using synchrotron radiation powder diffraction data: unbiased refinement strategy. J. Appl. Crystallogr. 33 (2000) 95-102.

van Dijen, F. K.; Metselaar, R.; Helmholdt, R. B.: Neutron diffraction study of beta' - sialon. J. Mater. Sci. Lett. 6 (1987) 1101-1102.

Vanderbilt, D.: Soft self-consistent pseudopotentials in a generalized eigenvalue formalism. Phys. Rev. B41 (1990) 7894-7895.

Van de Walle, A.; Ceder, G.: Automating First-Principles Phase Diagram Calculations. J. Phase Equilibria. 23 (2002) 348-359.

Vinograd, V. L.; Sluiter, M. H. F.; Winkler, B.; Putnis, A.; Gale, J. D.: Thermodynamics of mixing and ordering in silicates and oxides from static lattice energy and ab initio calculations. In: Warren M., Oganov A. and Winkler B. (eds) First-Principles Simulations: Perspectives and Challenges in Mineral Sciences (Deutsche Gesellschaft für Kristallographie. Berichte aus Arbeitskreisen der DFK 14) (2004) pp. 143-151.

Vinograd, V. L.; Perchuk, L. L.; Gerya, T. V.; Putnis, A.; Winkler, B.; Gale, J. D.: Order/disorder phase transition in cordierite and its possible relationship to the development of symplectite reaction textures in granulites. Petrology 15 (2007) (Translated from Petrologia 15(5) (2007) 459-473).
Vinograd, V. L.; Winkler, B.; Putnis, A.; Kroll, H.; Milman, V.; Gale, J. D.; Fabrichnaya, O. B.: Thermodynamics of pyrope - majorite, $\mathrm{Mg}_{3} \mathrm{Al}_{2} \mathrm{Si}_{3} \mathrm{O}_{12}-\mathrm{Mg}_{4} \mathrm{Si}_{4} \mathrm{O}_{12}$, solid solution from atomistic model calculations. Molecular Simulations. 32(2) (2006) 86-99.

Von Dreele, R. B.; Larson, A. C.: Programm GSAS General Structure Analysis System, Los Alamos National Laboratory, Los Alamos. (2001).

Warren, M. C.; Dove, M. T.; Myers, E. R.; Bosenick, A.; Palin, E. J.; Sainz-Diaz, C. I.; Guiton, B. S.: Monte Carlo methods for the study of cation ordering in minerals. Mineral. Mag. 65 (2001) 221-248.

Wilson, D. J.; Winkler, B.; Juares-Arellano, E. A.; Friedrich, A.; Knorr, K.; Pickard. C. J.; Milman, J.: Virtual crystal approximation study of nitridosilicates and oxonitridoaluminosilicates. J. Phys. Condensed Matter (2007) Submitted.

Winkler, B.; Dove, M. T.; Leslie, M.: Static lattice energy minimization and lattice dynamics calculations on aluminosilicate minerals. Am. Min. 76 (1991) 313-331.

Winkler, B.; Pickard, C.; Milman, V.: Applicability of quantum mechanical 'virtual crystal approximation' to study $\mathrm{Al} / \mathrm{Si}$-disorder. Chem. Physics Lett. 362 (2002) 266-270.

Wang, P.-L.; Werner, P.-E.; Gao, L.; Harris, R. K.; Thompson, D. P.; Ordering of nitrogen and oxygen in nitrogen-containing melilites $\mathrm{Y}_{2} \mathrm{Si}_{3} \mathrm{O}_{3} \mathrm{~N}_{4}$ and $\mathrm{Nd}_{2} \mathrm{Si}_{2.5} \mathrm{Al}_{0.5} \mathrm{O}_{3.5} \mathrm{~N}_{3.5}$. J. Mater. Chem. 7(10) (1997) 2127-2130. 